\title{
A Review of Current Development of Graphene Mechanics
}

\author{
Qiang Cao ${ }^{1, *}$, Xiao Geng ${ }^{2}$, Huaipeng Wang ${ }^{2}$, Pengjie Wang ${ }^{1}$, Aaron Liu ${ }^{1}$, Yucheng Lan ${ }^{3}$ \\ and Qing Peng $2,4, *$ iD \\ 1 The Institute of Technological Sciences, Wuhan University, Wuhan 430072, China; \\ pjwang@whu.edu.cn (P.W.); aaronyjliu@gmail.com (A.L.) \\ 2 School of Power and Mechanical Engineering, Wuhan University, Wuhan 430072, China; \\ xiaogeng@whu.edu.cn (X.G.); wanghuaipeng1998@163.com (H.W.) \\ 3 Department of Physics and Engineering Physics, Morgan State University, Baltimore, MD 21251, USA; \\ Yucheng.Lan@morgan.edu \\ 4 Nuclear Engineering and Radiological Sciences, University of Michigan, Ann Arbor, MI 48109, USA \\ * Correspondence: caoqiang@whu.edu.cn (Q.C.); qpeng.org@gmail.com (Q.P.); \\ Tel.: +86-137-0129-2834 (Q.C.); +1-734-763-3866 (Q.P.)
}

Received: 20 August 2018; Accepted: 30 August 2018; Published: 6 September 2018

\begin{abstract}
Graphene, a two-dimensional carbon in honeycomb crystal with single-atom thickness, possesses extraordinary properties and fascinating applications. Graphene mechanics is very important, as it relates to the integrity and various nanomechanical behaviors including flexing, moving, rotating, vibrating, and even twisting of graphene. The relationship between the strain and stress plays an essential role in graphene mechanics. Strain can dramatically influence the electronic and optical properties, and could be utilized to engineering those properties. Furthermore, graphene with specific kinds of defects exhibit mechanical enhancements and thus the electronic enhancements. In this short review, we focus on the current development of graphene mechanics, including tension and compression, fracture, shearing, bending, friction, and dynamics properties of graphene from both experiments and numerical simulations. We also touch graphene derivatives, including graphane, graphone, graphyne, fluorographene, and graphene oxide, which carve some fancy mechanical properties out from graphene. Our review summarizes the current achievements of graphene mechanics, and then shows the future prospects.
\end{abstract}

Keywords: graphene; mechanics; strain; defect; mechanical reinforcement; review

\section{Introduction}

Graphene, a mechanically excellent material with Young's modulus of $1 \mathrm{TPa}$ and intrinsic strength of $130 \mathrm{GPa}$ [1], has received significant interests since its discovery in 2004. Mechanical properties of graphene are part of the hottest topics in graphene research. Many articles about discoveries of mechanical properties have been published. These discoveries are helpful for the applications of graphene, because they have provided the data that reveal the mechanical nature of graphene. Beyond that, the data play an important role in designing graphene-based devices or other usages like graphene coating.

Recent theoretical and experimental studies on graphene mechanics are reviewed here. In Section 2, the mechanical properties of graphene are discussed comprehensively. Section 3 focuses on the mechanical properties of bilayer graphene and multilayer graphene. Section 4 deals with the influence of defects on mechanical properties of graphene. Section 5 is devoted to electronic properties of graphene modified by strain engineering. Section 6 shows the influences of strain and defects on 
the optical properties. Section 7 presents temperature effect on mechanical properties of graphene. Section 8 is the mechanics of graphene derivatives.

In the final section, the prospects for potential applications of mechanical properties are highlighted.

\section{Mechanical Properties of Graphene}

The results of the existing experimental and theoretical work on the mechanical properties of monolayer graphene are summarized in Table 1, including Young's modulus, 2D Young's modulus, Poisson's ratio, material strength, and fracture toughness. From Table 1, we can see how excellent the graphene is for all kinds of potential application, such as graphene composites, in which graphene can be a strong component resisting external loads. On the other side, the theoretical work usually goes further than the experimental work. It can be noticed that some properties need to be studied experimentally, such as Poisson's ratio, shear strength, bending rigidity (normal bending stiffness) and Gaussian bending stiffness. Particularly, the data of Poisson's ratio from different theoretical work are scattered, for example, the data by FEM method in Ref. [2] even differ from the data by MMC method in Ref. [3] by two orders of magnitude. Furthermore, monocrystal graphene is a kind of anisotropic 2D material. People struggle to study its mechanical properties in both armchair and zigzag directions. Unfortunately, due to the high difficulty of controlling the testing angle, researchers have to assume that graphene is approximately an isotropic material [1].

The detailed discussions will be presented below which cover the topics of tension, compression, fracture, shearing, bending, friction, and dynamics properties of graphene. 
Table 1. Mechanical Properties of Monolayer Graphene.

\begin{tabular}{|c|c|c|c|c|c|}
\hline Method & Young's Modulus (TPa) & $\begin{array}{c}\text { 2D Young's } \\
\text { Modulus (N/m) }\end{array}$ & Poisson's Ratio & Strength (GPa) & $\begin{array}{c}\text { Fracture Toughness (MPa } \\
\sqrt{\mathrm{m}})\end{array}$ \\
\hline \multicolumn{6}{|l|}{ Experiment } \\
\hline AFM-based nanoindentation [1] & $1.0 \pm 0.1[1]$ & $340[1]$ & - & $\begin{array}{c}130 \text { (Intrinsic strength) } \\
\text { [1] } \\
90 \sim 94[4]\end{array}$ & - \\
\hline In situ microscale tensile testing [5] & - & - & - & - & $\begin{array}{c}4.0 \pm 0.6 \text { (for CVD graphene) } \\
{[5]}\end{array}$ \\
\hline \multicolumn{6}{|l|}{ Simulation } \\
\hline Density functional theory (DFT) & $1.029[6], 1.05[7]$ & $345[6]$ & $0.149[6], 0.186[7]$ & 110(a), 121(z) [7] & - \\
\hline Monte Carlo simulation & & & $\approx 0.1[8]$ & & \\
\hline $\begin{array}{l}\text { Molecular dynamics } \\
\text { (MD)/Molecular Mechanics (MM) } \\
\text { simulation }\end{array}$ & $\begin{array}{c}1.533(\mathrm{a}) \\
1.111(\mathrm{z}) \text { (Morse) 0.879(a), } \\
1.273(\mathrm{z})(\text { AMBER) [9] } \\
0.96[10]\end{array}$ & $320[10]$ & $\begin{array}{l}0.102 \sim 0.175[9] \\
0.28 \pm 0.03[11]\end{array}$ & $\begin{array}{c}107(\mathrm{a}), 90(\mathrm{z})[12] \\
86.84(\mathrm{a}), 102.24(\mathrm{z})[13]\end{array}$ & $\begin{array}{c}3.44[5] \\
\text { 3.38(a), 3.05(z) (Mode I) } \\
\text { 2.87(a), 3.06(z) (Mode II) [14] }\end{array}$ \\
\hline $\begin{array}{l}\text { Finite element method } \\
\text { (FEM)/Modified } \\
\text { molecular-continuum model (MMC) }\end{array}$ & $\begin{array}{c}\approx 1.03(\mathrm{a}), \approx 1.1(\mathrm{z})[2] \\
1.040(\mathrm{a}), 0.992(\mathrm{z})[15]\end{array}$ & & $\begin{array}{l}\approx 0.08(\mathrm{a}), \approx 0.06(\mathrm{z})[2] \\
1.285(\mathrm{a}), 1.441(\mathrm{z})[15]\end{array}$ & $98[4]$ & $\begin{array}{c}\text { 3.13(a), 1.99(z) (Mode I) } \\
\text { 2.70(a), 3.73(z) (Mode II) [3] }\end{array}$ \\
\hline Method & Shear Modulus (GPa) & $\begin{array}{l}\text { Shear Strength } \\
\text { (GPa) }\end{array}$ & $\begin{array}{l}\text { Bending Rigidity } \\
\text { (Normal Bending } \\
\text { Stiffness) (eV) }\end{array}$ & $\begin{array}{l}\text { Gaussian Bending } \\
\text { Stiffness }(\mathrm{eV})\end{array}$ & \\
\hline \multicolumn{6}{|l|}{ Experiment } \\
\hline Silicon DPO [16] & 280 (for CVD graphene) [16] & - & - & - & \\
\hline \multicolumn{6}{|l|}{ Simulation } \\
\hline Density functional theory (DFT) & - & - & $1.44[17]$ & $-1.52[17]$ & \\
\hline $\begin{array}{c}\text { Molecular dynamics } \\
\text { (MD)/Molecular Mechanics (MM) } \\
\text { simulation }\end{array}$ & $\begin{array}{c}\text { 36 96(a), 59 138(z) [18] } \\
\text { 353(Morse), 277(AMBER) [9] } \\
\text { 340 370(a), 430 470(z) (AIREBO) [19] }\end{array}$ & $\approx 60[19]$ & $0.819 \sim 2.385[20]$ & - & \\
\hline $\begin{array}{l}\text { Finite element method } \\
\text { (FEM)/Modified } \\
\text { molecular-continuum model }\end{array}$ & $228[15]$ & - & - & - & \\
\hline
\end{tabular}




\subsection{Tension and Compression}

When graphene is loaded with tensile stress, large deformation could be induced along the stress orientation. Young's modulus, the ratio of tensile stress to tensile strain under small strains, characterizes the stiffness of graphene against the tensile stress. Los et al. [21] found that the value of Young's modulus could rise dramatically with a tensile strain as a result of suppression of rippling. To explore the underlying mechanism for the surprising mechanical properties, two major deformation modes, PW-I and PW-II, were proposed [22]. In the PW-I mode, bond angles change while bond lengths remain. In PW-II mode, bond lengths change while bond angles remain. Both modes relate to the angle bending interaction and bond stretching interaction, which are two major interactions in graphene.

When graphene is stretched in one in-plane direction and the tensile strain exceeds about $6 \%$, the graphene will expand its size in the direction vertical to the tensile direction. This interesting phenomenon is noted as Negative Poisson's Ratio (NPR), which can be explained by the PW-II mode due to the lower energy of graphene in this condition [22]. Jiang et al. [23] established an inclined plate model to predict Poisson's ratio of arbitrary-size graphene ribbons, demonstrating that NPR is dependent on how the width and the warping amplitude of the edge interact. An analytic formula and an analytic phase diagram were promoted from this model showing how the sign and value of Poisson's ratio changed by various graphene's morphology. Via molecular dynamics simulations, Deng et al. [24] found that the NPR of graphene only occurs in uniaxial tension along the armchair direction. This feature will not disappear until the temperature is over $2400 \mathrm{~K}$ and can also happen in bilayer and multilayer graphene.

Based on the relationship between tensile strain and stress, some experiments are applied to measure tensile properties of graphene. Among those experiments, the nanoindentation conducted with an atomic force microscope (AFM), shown in Figure 1, is widely used. Lee et al. [1] first directly measured the value of two-dimensional Young's modulus $(340 \mathrm{~N} / \mathrm{m})$, a third-order elastic stiffness of monolayer graphene $(-690 \mathrm{~N} / \mathrm{m})$, and intrinsic strength (130 GPa) by AFM-based nanoindentation on monolayer graphene sheets. In the process of nanoindentation, graphite flakes are deposited onto the substrate where there are some circular wells. After monolayer graphene sheets are found among these flakes by a microscope, their thicknesses are detected by Raman spectroscopy to make sure that they are single-layered. The probe of AFM is used to indent the center of the circular area of the monolayer graphene suspended on wells, which is under tensile loads in all in-plane directions. Before the graphene sheets are broken by the probe, non-destructive indentation is repeated for several times and the recorded force-displacement data are checked to confirm that the responses of these sheets are merely elastic behavior. Then, the sheets are fractured by the probe. The force-displacement data are analyzed, and tensile properties are obtained.

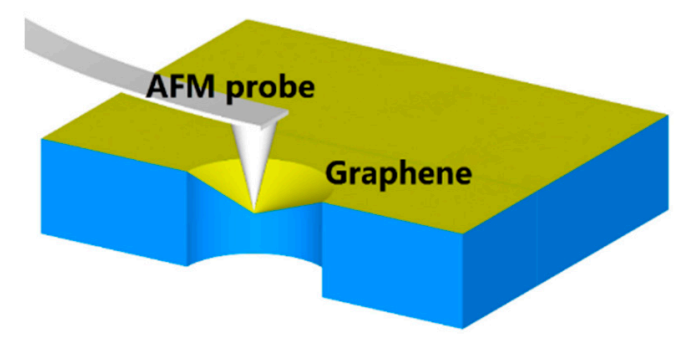

Figure 1. Schematic of AFM-based nanoindentation.

Androulidakis et al. [25] proposed a different experiment to derive the axial stress-strain curve of graphene experimentally. The Raman spectroscopy of graphene should be obtained first. Then, the spectroscopic data are transformed into true axial stress-strain curves with the estimated stress-strain sensitivity of the 2D peak in the spectroscopy. 
When graphene is under compression by in-plane loads beyond a limit, it will be buckling. Buckling of graphene means when it is subject to compressive stress on the boundary, a sudden sideways deflection of the central part of the graphene sheet occurs. This may happen even though the stresses in the structure are still much smaller than those needed to cause failure of graphene.

The experiment performed by Tsoukleri et al. [26] made monolayer graphene under both tension and compression and revealed some buckling characteristics of graphene. The monolayer graphene sheets exfoliated mechanically from graphite are transferred to two types of small PMMA cantilever beams, close to the fixed end. As can be seen in Figure 2, in the type (a), the graphene sheet is bare on the beam, but it is embedded between a PMMA layer and a layer of SU8 photoresist on the beam in the type (b). With a vertical load on the suspended end, the graphene sheet is deformed together with the beam when its Raman spectrum is measured. Through analyzing the relationship between strain and the data from Raman spectra and mechanical parameters of the beam, Tsoukleri et al. figured out an axial buckling stress of $6 \mathrm{GPa}$ for monolayer graphene. For embedded graphene at strain beyond $-0.7 \%$, the sheet buckles as it does at strain of $-0.03 \%$ in air because of the weakened interface between graphene and PMMA, which means buckling strain can be increased to higher values by using harder matrices or stronger interfaces between the graphene and polymer matrix. The tensile behaviors of both bare and embedded graphene were similar.

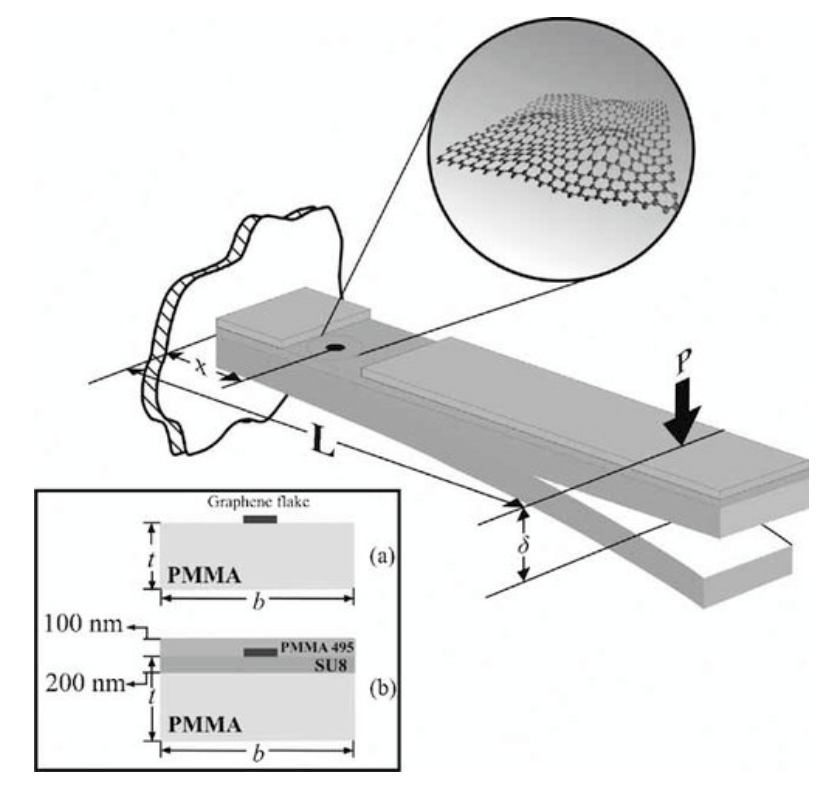

Figure 2. Cantilever beams for (a) bare and (b) embedded graphene sheets [26]. Copyright (2009) John Wiley and Sons.

There is also some theoretical work of prediction for buckling graphene. Pradhan [27] reformulated higher-order shear deformation theory (HSDT) and derived the equations of motion of nonlocal theories to study buckling characteristics of graphene. In the literature [28], using nonlocal continuum mechanics, Pradhan et al. also investigated the small scale effect on the buckling of biaxially compressed monolayer graphene, and found that the influence of nonlocal effects on biaxially compressed monolayer graphene is smaller than that on uniaxially compressed graphene, when side lengths of graphene are small and nonlocal parameter values are large. By a continuum-based approach, Civalek [29] analyzed the influences of the boundary conditions, applied loads and skew angles on buckling loads of the skew shaped graphene. For graphene sheet with small skew angles, the influence of the aspect ratio on buckling loads is more significant than that of other skew angles. For the same graphene sheets under pure shear loads, their buckling loads are usually bigger than that of conditions where they are under other kinds of loads. For shew graphene with side lengths shorter 
than $\approx 15 \mathrm{~nm}$ in SSSS boundary condition, smaller shew angles causes higher buckling loads, which is much more significant for shorter side lengths around $\approx 5 \mathrm{~nm}$.

Apart from compression by in-plane loads, the compression by out-plane loads can also happen on graphene. In widely used AFM-based nanoindentation, it is obvious that the carbon atoms in the center of the circular area are compressed by the indenter, but the characteristics of the mechanical response of these atoms are known less. In order to determine out-of-plane elastic properties of convexly curved graphene including its atomic-site-specific variation, Ashino et al. [30] triggered the out-of-plane displacement of the "single" atom using atomic force microscope (AFM), and then solved out the relationship between the elasticity and out-of-plane displacement. The intrinsic modulus increases dramatically when the distance is over about 0.35 which is at atomic level. This discovery is shown in Figure 3. The out-of-plane elastic stiffness at the carbon-atom site becomes larger than that at the hollow site with the increasing out-of-plane displacement of the "single" atom.

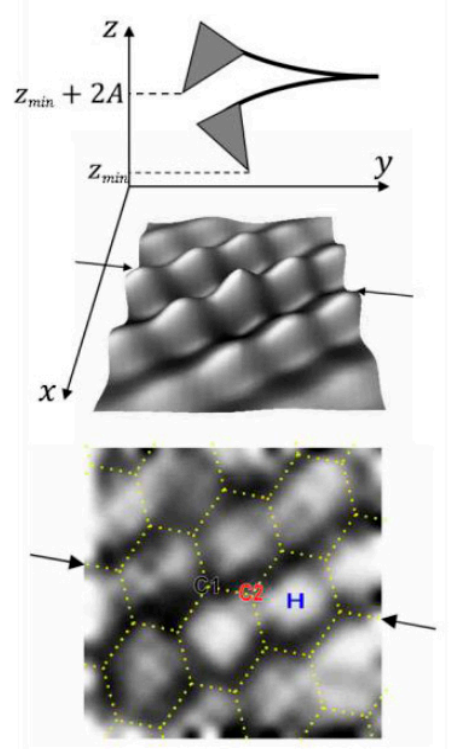

(a)

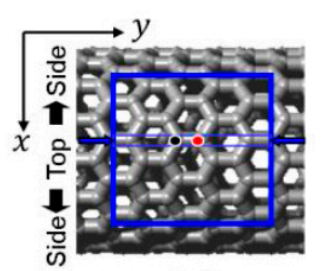

(b)

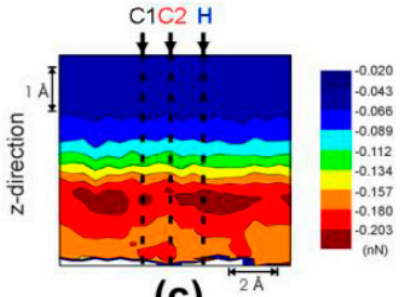

(c)

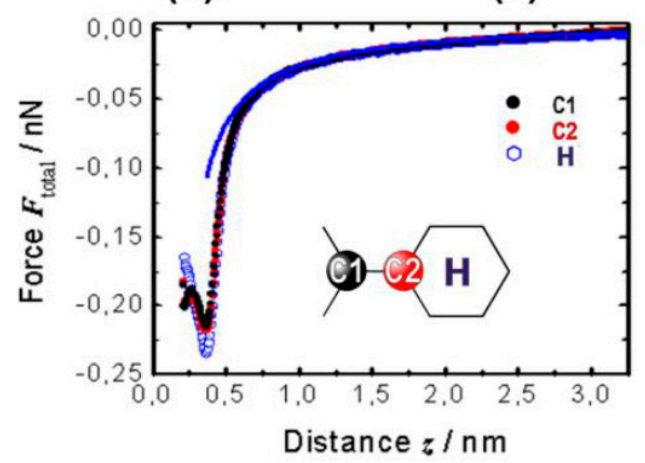

(d)

Figure 3. (a) Schematic illustration of a 3D-FFS measurement; (b) Schematic illustration of a 3D-FFS measurement; (c) 2D force field map; (d) Interatomic force vs. vertical distance $z$. Reprinted (adapted) with permission from [30].

\subsection{Fracture}

The graphene with cracks may fracture under tension. In general, fracture toughness of a material with a crack represents the ability to resist the fracture [31]. It usually determines the strength of large-area graphene with engineering issues [5]. Zhang et al. [5] proved that classic Griffith theory of brittle fracture is still applicable to graphene, and first measured the fracture toughness of CVD graphene by in situ microscale tensile testing.

Figure 4 [5] shows the principle of in situ microscale tensile testing. The bilayer graphene specimen is transferred by a dry transfer method to the sample stages of a microdevice specialized for testing. When the nanoindenter pushes the top shuttle, the displacement of the nanoindenter tip was transformed into the tension of graphene by inclined beams which make the two sample stages leave each other. On the gap of two sample stages, a pre-crack should be induced in the bilayer graphene specimen before the tension by focused iron beam (FIB) cutting. Through analyzing the experimental data from nanoindenter and sample stages and calculation, the fracture toughness of graphene can be characterized by critical stress intensity factor of $4.0 \pm 0.6 \mathrm{MPa} \sqrt{\mathrm{m}}$ and corresponding strain energy release rate of $15.9 \mathrm{~J} \cdot \mathrm{m}^{-2}$. By molecular dynamics (MD) simulations (REBO potential), Zhang et al. 
also found that the blunt crack tip with a bigger notch radius can result in larger critical stress intensity factor of graphene.

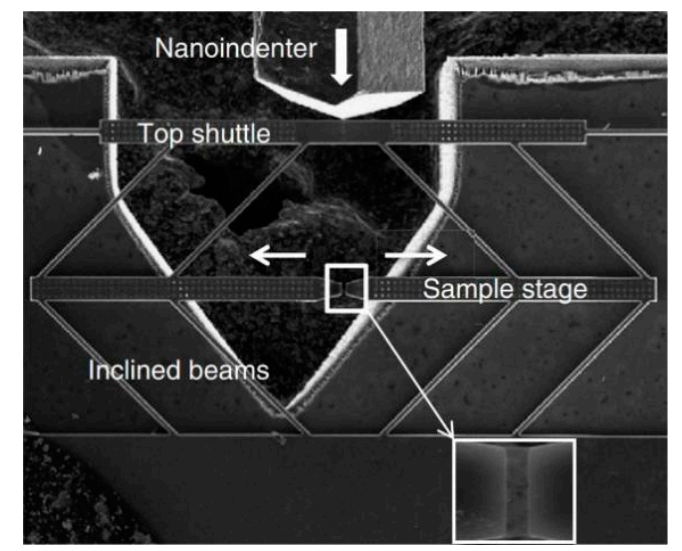

Figure 4. SEM image showing the in situ tensile testing with a microdevice. Inset is the magnified image of the boxed region showing graphene across the gap of the sample stage. Reprinted (adapted) with permission from [5]. Copyright (2014) Springer Nature.

Graphene can also be fractured by tearing. Moura et al. [32] studied fracture mechanics of torn graphene. By molecular dynamics, they simulated how the out-of-plane force makes the crack propagate in graphene and found that initial crack length can determine the crack's path and the edge structure. The fracture toughness of graphene was also calculated to be $11.24 \mathrm{~J} \cdot \mathrm{m}^{-2}$ $\left(3.82 \times 10^{-9} \mathrm{~J} \cdot \mathrm{m}^{-1}\right)$. Using scalable nanoimprint-style contact techniques, Annett et al. [33] induced the parallel self-assembly of graphene ribbons in controlled shape. They built a fracture-mechanics model showing how the graphene-graphene interface is formed by thermodynamic forces. These two cases indicated the hope that graphene sheets can be patterned by tearing in future nanomanufacturing, which is helpful for making two-dimensional micro- and nanodevices complex in shape.

Combining molecular dynamics (MD) simulations and the fracture mechanics analysis, Han et al. [34] showed that the fracture forces from the spherical indenter cannot be directly mapped onto the uniaxial strength but cylindrical indenters can. The strength estimated with a cylindrical indenter is not sensitive to the indentation site and angular misalignments from human error or the apparatus limitations. Moreover, there is possibility for measuring tensile strength from nanoindentation experiments.

\subsection{Shearing}

Shear deformations can be described as follows: one boundary of graphene is fixed at its free-load equilibrium structure, while constant forces are applied at all atoms of the opposite boundary. The directions of the forces are parallel to the edges, like armchair edge and zigzag edge shown in Figure 5.

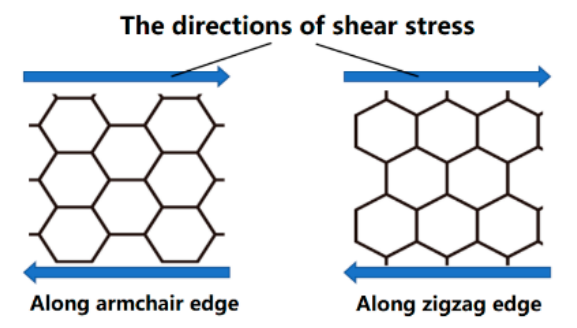

Figure 5. Two cases in which shear stresses are loaded on graphene. The shear stress in the left picture is along armchair edge and in the right picture is along zigzag edge. 
Shear modulus of graphene has been calculated by different simulation methods. For molecular mechanics, Sakhaee-Pour [15] found that the shear modulus is $0.228 \mathrm{TPa}$ along armchair edge and $0.213 \mathrm{TPa}$ along zigzag edge. For Monte Carlo simulation, Zakharchenko et al. figured out temperature-dependent shear modulus. Assuming the thickness of graphene is $0.34 \mathrm{~nm}$, it changes around $0.47 \mathrm{TPa}$ and reaches to the highest value of $0.483 \mathrm{TPa}\left(10.27 \pm 0.17 \mathrm{eV} \cdot \AA^{-2}\right)$ [8] at around $700 \mathrm{~K}$. For molecular dynamics (MD) simulation, Tsai et al. [35] obtained the shear modulus of graphene at $0 \mathrm{~K}$ as $0.358 \mathrm{TPa}$ with AMBER force field. Using AIREBO force field, Min et al. [19] showed the shear modulus in armchair direction ranging from $0.34 \mathrm{TPa}$ to $0.37 \mathrm{TPa}$ and in zigzag direction ranging from 0.43 to $0.47 \mathrm{TPa}$. The temperature varies from 0 to $2000 \mathrm{~K}$. For both armchair and zigzag direction, the shear moduli at first increase with the temperature, and then begin to decrease when it is beyond $800 \mathrm{~K}$ [19]. Generally, the shear modulus in armchair direction is smaller than that in zigzag direction, which can be concluded from Table 1. However, the mechanism of this phenomenon is unclear, which needs more investigations.

Apart from shear modulus, Min et al. also plotted a figure with results from MD, showing that shear strength almost decreases linearly from $\approx 60 \mathrm{GPa}$ to $\approx 30 \mathrm{GPa}$ when the temperature increases from $0 \mathrm{~K}$ to $2000 \mathrm{~K}$ [19]. Recently, Tarek et al. [18] studied how aspect ratio affects shear modulus and shear strength of graphene nanoribbons (GNR). The shear moduli in both armchair and zigzag directions show a drastic decline when length of the GNR increases from $2.5 \mathrm{~nm}$ to $25 \mathrm{~nm}$. In armchair direction it decreases from $96 \mathrm{GPa}$ to $36 \mathrm{GPa}$ and in zigzag direction it decreases from 138 to $59 \mathrm{GPa}$.

The values of shear modulus are dramatically scattered. In contrast to many theoretical investigations, few researchers have done experimental research to measure the shear modulus. These results are not convincing without experimental verification. Furthermore, the shear strength of graphene is rarely investigated.

A possible experimental method for shearing test of graphene, shown in Figure 6, can be similar to in situ microscale tensile testing. In Figure 6, the graphene is transferred to the sample stages of a microdevice generally similar to that in Figure 4, but the shape of the part contacting with graphene is different. Two bars extending from each side of sample stage are fixed with the opposite edges of graphene sheet by the fixer. When the nanoindenter pushes the top shuttle, the graphene sheet is deformed by shear forces from sample stages. The displacement of sample stages and geometric features including the width and length of graphene can be detected by SEM of TEM. The historical data of nanoindenter including its displacement and forces can also be recorded. The numerical relationship between the compression from the indenter and the shear forces loaded onto the graphene sheet can be known by the design of the microdevice. With these, the shear modulus and shear strength of graphene can be calculated indirectly according to its definition.

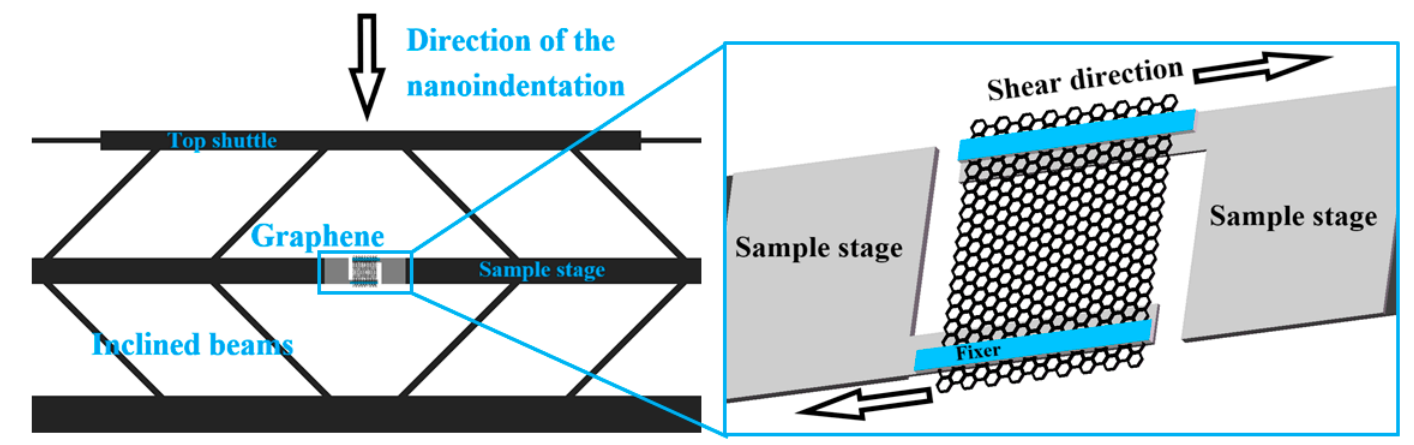

Figure 6. A schematic presenting a possible experiment method for measuring the shear modulus and shear strength of graphene. The pattern of the graphene sheet is not shown in the real scale. 


\subsection{Bending}

Bending means both ends of a sheet of graphene are made out of plane. For graphene, bending rigidity, also named as normal bending stiffness, is not studied as much as the tensile strength. The Gaussian bending stiffness is also noted less by people. Wei et al. [17] determined the bending rigidity and found it is $1.44 \mathrm{eV}$, approximately equal to that of lipid bilayers of cells $(1 \sim 2 \mathrm{eV})$, therefore justifying the biological applications of graphene mechanically. Gaussian bending stiffness of graphene is also determined to be $-1.52 \mathrm{eV}$. The bending behavior has many remarkable functions, such as controlling the morphology of graphene under a loaded force, influencing its electrical, thermal, and magnetic properties.

The bilayer graphene bending warps like a sandwich lamination structure which has a fairly hard core, and the bending warpage can be estimated by a first-order deformation theory [36]. The bending properties of multi-layer graphene mainly depend on the interlayer interaction, which can be investigated using molecular dynamics (MD) simulations. The MD results showed that the in-plane Young's modulus is three orders higher than that of interlayer shear modulus [37].

\subsection{Friction}

Zhang et al. acquired the friction behavior of a graphene flake sliding on a supported graphene substrate by making use of a graphene-spring model, as well as verify that friction increases exponentially with decreasing stiffness [38]. They found that the depth of the indentation can indicate the friction of the soft substrate by the relationship between friction and substrate deformation. Furthermore, the stiffness-dependent friction has a close relationship with stiffness-dependent deformation of graphene [38]. With a softer substrate and a larger deformation, the friction energy will be larger. This study provides a basic knowledge for stiffness-dependent friction of graphene.

Apart from experimental studies of graphene friction, theoretical studies have been conducted on various factors affecting graphene friction. Molecular dynamics (MD) simulations were applied to investigate fundamental atomic-scale mechanisms of graphene friction, in which some models were built to explain that compared with the bulk grain region, the grain boundary region has greater contribution to the friction [39]. The effect of external in-plane strain on the frictional behavior of multilayer graphene was studied with LAMMPS (a software specialized for MD simulations), and the conclusion is that the strain-induced friction coefficient variations are attributed to atomic-scale contacted area changing [40].

\subsection{Dynamics Properties}

In addition to the mechanical properties related to statics, dynamics properties are also important for the research of graphene mechanics. The dynamics properties of graphene mainly include eigenfrequencies (also called natural frequencies), mode shapes and power spectral density properties. To obtain these properties, some models were proposed in recent years, which are summarized in Table 2. 
Table 2. Models for studying the dynamics properties of monolayer graphene.

\begin{tabular}{|c|c|c|c|}
\hline Year & Researchers & Models/Methods & Subjects Investigated \\
\hline 2008 & Sakhaee-Pour et al. [41] & $\begin{array}{l}\text { Molecular structural } \\
\text { mechanics }[42,43]\end{array}$ & $\begin{array}{l}\text { Eigenfrequencies and mode } \\
\text { shapes }\end{array}$ \\
\hline 2009 & Hashemnia et al. [44] & $\begin{array}{l}\text { Molecular structural } \\
\text { mechanics }[42,43]\end{array}$ & $\begin{array}{l}\text { Eigenfrequencies and mode } \\
\text { shapes }\end{array}$ \\
\hline 2010 & Sadeghi et al. [45] & $\begin{array}{l}\text { A hybrid atomistic-structural } \\
\text { element }\end{array}$ & $\begin{array}{l}\text { Linear and nonlinear } \\
\text { vibrations }\end{array}$ \\
\hline 2010 & Gupta et al. [46] & $\begin{array}{l}\text { Molecular mechanics (MM) } \\
\text { and an equivalent continuum } \\
\text { structure (ECS) }\end{array}$ & $\begin{array}{l}\text { Eigenfrequencies of axial and } \\
\text { bending modes of monolayer } \\
\text { graphene with different } \\
\text { charities, aspect ratios }\end{array}$ \\
\hline 2010 & Ansari et al. [47] & $\begin{array}{l}\text { A nonlocal elasticity model } \\
\text { based on generalized } \\
\text { differential quadrature (GDQ) } \\
\text { method and molecular } \\
\text { dynamics (MD) simulation. }\end{array}$ & Eigenfrequencies \\
\hline 2010 & Scarpa et al. [48] & $\begin{array}{l}\text { An equivalent } \\
\text { atomistic-continuum finite } \\
\text { element model }\end{array}$ & $\begin{array}{l}\text { Eigenfrequencies and acoustic } \\
\text { wave propagation } \\
\text { characteristics of graphene } \\
\text { nanoribbons }\end{array}$ \\
\hline 2011 & Mianroodi et al. [49] & A membrane model & $\begin{array}{l}\text { Nonlinear vibrational } \\
\text { properties }\end{array}$ \\
\hline 2011 & Chowdhury et al. [50] & Molecular mechanics (MM) & Transverse vibrations \\
\hline 2012 & Bekir et al. [51] & Modified couple stress theory & $\begin{array}{l}\text { The size effect on vibration of } \\
\text { monolayer graphene on an } \\
\text { elastic matrix }\end{array}$ \\
\hline 2012 & Baykasoglu et al. [52] & $\begin{array}{l}\text { A finite element method based } \\
\text { on molecular mechanics (MM) }\end{array}$ & $\begin{array}{l}\text { 2D and 3D modal and } \\
\text { transient analyses }\end{array}$ \\
\hline 2013 & Alyokhin et al. [53] & Molecular mechanics (MM) & $\begin{array}{l}\text { Eigenfrequencies and the } \\
\text { buckling modes }\end{array}$ \\
\hline 2016 & Mirparizi et al. [54] & $\begin{array}{l}\text { A finite element method based } \\
\text { on molecular mechanics (MM) }\end{array}$ & $\begin{array}{l}\text { Eigenfrequencies and mode } \\
\text { shapes for cantilever and } \\
\text { bridged monolayer graphene }\end{array}$ \\
\hline
\end{tabular}

The eigenfrequencies and mode shapes of graphene change with various boundary conditions. The size of the graphene sheet are also affected by other conditions. Generally, eigenfrequencies decrease for bigger-size or bigger-side-length graphene sheets, and for the same mode of almost the same size graphene sheet, eigenfrequencies are a little higher in armchair graphene than in zigzag graphene [46,47]. Surprisingly, some of the bending vibrations of graphene ribbons are in-plane vibrations [46]. The buckling modes of graphene sheets mainly rely on the velocity of the specified displacements of the sheet edge [53]. Moreover, various modes and eigenfrequencies of the vibration of a free monolayer graphene obtained via MM simulations disagree with those from its equivalent continuum structure made of a homogeneous linear elastic material, which may indicate the limitation of continuum theory in simulations for dynamics properties [46].

\section{Mechanical Properties of Bilayer and Multilayer Graphene}

\subsection{Bilayer Graphene}

The mechanical properties of bilayer graphene are summarized in Table 3 for comparing with that of monolayer graphene. Generally, bilayer and multilayer graphene have very different mechanical properties from that of monolayer graphene. To obtain these parameters, advanced experimental setup needs to be built. So far, for bilayer graphene, there is only one experimental method listed in the table 
which is in situ microscale tensile testing [5]. In future, we expect the AFM-based nanoindentation setup for bilayer graphene could be constructed, so that more parameters, such as Young's modulus and Poisson's ratio, could be measured precisely.

Table 3. Mechanical Properties of Bilayer Graphene.

\begin{tabular}{|c|c|c|c|c|c|}
\hline Methods & $\begin{array}{l}\text { Young's Modulus } \\
\text { (TPa) }\end{array}$ & $\begin{array}{l}\text { Poisson's } \\
\text { Ratio }\end{array}$ & $\begin{array}{l}\text { In-Plane Shear } \\
\text { Modulus (GPa) }\end{array}$ & $\begin{array}{c}\text { Intrinsic } \\
\text { Strength (GPa) }\end{array}$ & $\begin{array}{c}\text { Fracture } \\
\text { Toughness } \\
(\mathbf{M P a} \sqrt{\mathbf{m}})\end{array}$ \\
\hline $\begin{array}{l}\text { In situ microscale } \\
\text { tensile testing [5] }\end{array}$ & - & - & - & - & $29.5[55]$ \\
\hline Molecular mechanics & $1.030[56]$ & 0.195 [57] & $482[58]$ & - & - \\
\hline $\begin{array}{l}\text { Molecular dynamics } \\
\text { simulation (MD) }\end{array}$ & 0.8 [59], 0.795 [35] & $0.272[35]$ & 318 [35] & - & - \\
\hline $\begin{array}{l}\text { Molecular structural } \\
\text { mechanics (MM) }\end{array}$ & $1.007(\mathrm{a}) 1.005(\mathrm{z})[60]$ & $\begin{array}{c}0.0803(\mathrm{a}) \\
0.112(\mathrm{z})[60]\end{array}$ & $453.3[60]$ & - & - \\
\hline $\begin{array}{l}\text { Density functional } \\
\text { theory (DFT) }\end{array}$ & $\begin{array}{c}0.867(\mathrm{AA}), 0.977(\mathrm{AB}) \\
0.953 \pm 0.0214 \text { (for } \\
\text { twisted bilayer } \\
\text { graphene) [61] }\end{array}$ & - & - & $\begin{array}{c}\text { 96.97 111.23 } \\
\text { (for twisted } \\
\text { bilayer } \\
\text { graphene) [61] }\end{array}$ & - \\
\hline
\end{tabular}

Some brief explanatory notes are put in the brackets after the data. The lower-case letters including " $\mathrm{a}$ " and " $\mathrm{z}$ " represent the load directions of corresponding graphene sheets. The letter "a" means the load direction is armchair and " $\mathrm{z}$ " means zigzag. "AA" and " $\mathrm{AB}$ " mean the ways how bilayer graphene sheets are stacked. AA-stacked bilayer graphene sheets are completely coincident when they are looked at in the direction vertical to the plane, but for AB-stacked ones, in the center of each hexagonal hole of the top layer, one atom of the bottom layer can be seen. Young's modulus and the intrinsic strength of twisted bilayer graphene by DFT are also listed in the table.

Apart from the mechanical properties that monolayer graphene has, bilayer graphene also possesses a unique property: the interlayer shear interaction. Based on pressurized microscale bubble loading devices, Wang et al. [58] first measured an interlayer shear stress of $40 \mathrm{KPa}$ for the zone outside the bubble edge of bilayer graphene, which seems to be an effective experiment for characterizing the interlayer shear properties of nanoscale-thickness membranes. Particularly, a bilayer graphene may have some $\mathrm{sp}^{3}$ bonds connecting two carbon atoms from different layers, just like the model shown in Figure 7. These $\mathrm{sp}^{3}$ bonds play important role in the interlayer shear interaction of bilayer graphene. Mirparizi et al. [54] exploited the molecular mechanics (MM) simulation to study the interlayer shear effects on vibrational behavior of cantilever and bridged bilayer graphene. Results showed that the interlayer shear interaction increases the natural frequencies because of the prevention to the lateral displacements by shear forces. Molecular dynamic (MD) simulations [62] also show sp ${ }^{3}$ bonds can reduce Young's modulus, the tensile strength and the critical fracture strain, but strengthen the interlayer shear modulus and the load transfer rate, thus making graphene sheets more stable under axial compression.

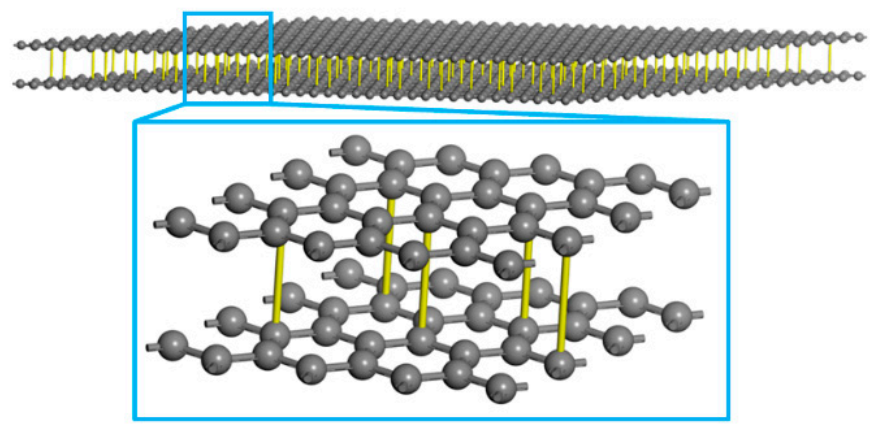

Figure 7. $\mathrm{Sp}^{3}$ bonds randomly distributed (shown in yellow) between bilayer graphene sheets. 
For elastic properties of bilayer graphene including Young's modulus, shear modulus and Poisson's ratio, now there are only some theoretical studies. The Young's modulus of bilayer graphene is $0.8 \mathrm{TPa}$, smaller than that of monolayer graphene (1TPa), which was shown by the results from the nanoindentation simulated by molecular dynamics (MD) [59]. What's more, it will decrease by $14 \%(0.69 \mathrm{TPa})$ when the temperature declines from room temperature $(\mathrm{T}=300 \mathrm{~K})$ to a low temperature $(\mathrm{T}=20 \mathrm{~K})$ [59]. However, up to now, no article has reported any experimental results from the nanoindentation of bilayer graphene to verify the result of $0.8 \mathrm{TPa}$, and several articles $[35,56,60]$ show different results of $\approx 1.0 \mathrm{TPa}$. Young's modulus of twisted bilayer graphene was found to be $953 \pm 21.4 \mathrm{GPa}$ [61], not dependent on twist angle and close to that of orientated bilayer graphene (977 for AB and 867 GPa for AA). Kordkheili et al. [60] established a molecular structural mechanics model to calculate the mechanical properties of bilayer graphene sheets. The results indicated that Young's modulus of bilayer graphene sheets declines almost linearly with increasing tensile strain while the shear modulus shows no dependence on shear strain. Poisson's ratio does not change with tensile strain. The thickness-wise stiffness gets large for smaller distance between the two layers.

The fracture behavior of bilayer monocrystal graphene with a pre-crack were studied by in situ microscale tensile testing [55]. It was observed that the crack globally propagated along a straight path vertical to the direction of tension, but locally it wriggled and developed some branches whose orientation (armchair direction) formed an angle about $30^{\circ}$ with pre-crack (zigzag direction), which has been theoretically predicted by Yin et al. [63] and Datta et al. [64]. In addition, with the fitted experimental data, the fracture toughness of graphene can be estimated to be $29.5 \mathrm{MPa} \sqrt{\mathrm{m}}$, which is much larger than the experimental results from Zhang et al. [5]. Main reason is the nonlinearity of graphene [55].

The simulations of fracture behavior of bilayer graphene were done by Muniz et al. [65] and Wang et al. [66] with molecular dynamics simulations and by Zhang et al. [61] with DFT calculation. For bilayer graphene sheets various in distribution of interlayer bonds [65], fracture is formed at the interface between pristine graphene and interlayer-bonded two-dimensional diamond-like domains and then propagates across the sheets, leading to brittle fracture. However, a transition to ductile failure with void formation and coalescence in structure happens when the spatial density of interlayer bonds is beyond a certain value. For tensed bilayer graphene sheets without interlayer bonds [66], the fracture strain is sensitive to chirality and loading direction. But these two properties of the armchair-zigzag bilayer graphene show no dependence on loading direction and it is fractured step by step. For bilayer graphene with twist or grain boundaries, Zhang et al. [61] adopted DFT to calculate intrinsic strength, critical failure strain, discovering that with increasing twist angle from $5^{\circ}$ to $42.1^{\circ}$, the intrinsic strength decreases from 111.23 GPa to $96.97 \mathrm{GPa}$ and critical failure stain decreases almost linearly from $24 \%$ to $19 \%$. For the bilayer graphene consisting of a monocrystal graphene sheet and a polycrystalline graphene sheet with grain boundaries, all of its mechanical properties are determined by the latter. Because of the lower energy and shorter $\mathrm{C}-\mathrm{C}$ bonds in grain boundaries, bilayer graphene with larger grain boundary angles own higher intrinsic strength.

As for buckling of bilayer graphene, Chandra et al. [67] confirmed that the critical buckling load of bilayer graphene is 20 times higher than that of monolayer graphene by atomistic finite element approaches. The buckling response of bilayer graphene is not sensitive to the aspect ratio but its critical buckling load decreases with increasing side-length.

For dynamics properties of bilayer graphene, several important models were established in recent years.

Chandra et al. [68] studied the vibrational properties of bilayer graphene by the atomistic finite element approach and continuum plate theory. They found the mode shapes of bilayer graphene are similar to those of monolayer graphene. It was also observed that bilayer graphene sheets own higher natural frequencies than monolayer graphene sheets do because of their larger bending stiffness, and their fundamental natural frequency decreases when the length and aspect ratio of sheets increase. 
Moreover, when the bilayer graphene sheet is big enough, armchair and zigzag models make no difference in dynamic properties, but it changes when the length of bilayer graphene is shorter than $3 \mathrm{~nm}$.

Proposing a geometrical-analytical method, Nazemnezhad et al. [69] investigated how tensile-compressive and shear effects of van der Waals (vdWs) interactions affect free vibration of cantilever bilayer graphene nanoribbons (CBGNRs). They concluded that low frequency numbers of CBGNRs are only affected by the interlayer shear modulus, while high frequency numbers are usually affected by the tensile-compressive modulus. Because low frequencies are easier to achieve than high frequencies, effects of shear modulus of vdWs interactions are more important.

Wang et al. [70] modeled the graphene sheet as a nonlocal plate with Eringen's nonlocal elasticity theory to investigate the small-scale effect on the pull-in instability and frequency of graphene sheets subjected to electrostatic and van der Waals forces. They reported that nonlocal elasticity reduces the pull-in voltages and fundamental frequencies, which is more significant for smaller-sized sheets.

Employing classical plate theory combined with nonlocal elasticity theory, Zhang et al. [71] studied how bilayer graphene sheets vibrate in a magnetic field to explain the small-scale effect. Independent of the side length, boundary conditions, aspect ratio and nonlocal parameter, the second interlayer vibration mode frequency is influenced by the magnetic field, enabling the first interlayer vibration mode frequency get close to the second one when the magnetic parameter is large enough.

$\mathrm{Wu}$ et al. [72] proposed an element-free framework and used it to analyze how boundary conditions, size of graphene sheets and nonlocal parameters affect the buckling behaviors of bilayer circular graphene sheets which rely on an elastic medium. It was reported that the OP buckling modes are only sensible to van der Waals forces. In 2018, they investigated the vibration behavior of bilayer graphene sheets in thermal environments [73]. The nonlocal elastic theory and classical plate theory were used to derive the governing equations. The element-free method is employed to analyze the vibration behavior of bilayer graphene sheets embedded in an elastic medium.

Furthermore, the influence of boundary conditions, nonlocal parameter, aspect ratio, side length, temperature, elastic foundation parameter and magnetic parameter on the vibration behavior of bilayer graphene sheets were investigated [71,73].

\subsection{Multilayer Graphene}

For multilayer graphene, people care about its twisting, friction and dynamics properties more than its elastic properties.

Cranford et al. [74] established a 2D mesoscopic model for a sheet of graphene utilizing coarse-grain bead-spring elements, with which they studied the ultralong twisted multilayer graphene ribbons. There is a distinct transition from a twisted (saddle-like) configuration to a helical (coil-like) configuration when imposed rotation and the number of graphene layers change.

Yang et al. [75] studied the relationship between the friction coefficient and the strain of multilayer graphene scratched by diamond with various scratch depths. The friction coefficient decreases under tensile strain but increases under compressive strain. The explanation was that the decreasing number of contacting atoms leads the friction coefficient decline when the strain increased from $-8 \%$ to $8 \%$.

Wang et al. [76] proposed a nonlinear elastic plate model to analyze the nonlinear vibration of multilayer graphene sheets. The nonlinear van der Waals interaction between any two layers is formulated in the model. The numerical results reveal the anti-phase vibration properties which is useful for making nano-switches and separating bilayer graphene sheets into single one.

With the nonlocal elasticity theory, Jomehzadeh et al. [77] investigated the nonlinear free vibration of multilayered graphene sheets. They got the large amplitude vibration solutions of triple layered graphene sheets with simply supported or clamped boundary conditions. The nonlinear behavior of triple layered graphene sheets is increased by van der Waals interaction.

Lu et al. [78] built a three-beam model to investigate the vibration of the multilayer graphene sheets under layerwise tension loads. The results from the model predicted that the tensile stress/strain of outmost monolayers in a multilayer graphene sheet can be much larger than those predicted by 
the widely used single-beam model [79]. Moreover, vibrational frequencies of a multilayer graphene sheet almost rely on the total tension. Based on these discoveries, a formula was derived for natural frequencies of multilayer graphene sheets under layerwise tension loads.

The vibration modes of multilayer graphene can be influenced by residual stress. With a scanning probe microscopy, Garcia-Sanchez et al. [80] measured the vibration in suspended multilayer graphene sheets, discovering a new kind of nanoscale vibration eigenmodes in which the maximum amplitude of vibration is at the free edges. By modeling the graphene sheets with the finite element method, they found the new eigenmodes resulting from residual stress up to 1.5 GPa caused by pressing or rubbing bulk graphite against another surface during the process of exfoliating graphene sheets.

\section{Influence of Defect on Mechanical Properties of Graphene}

Crystal defects refer to that the periodic arrangement rule in the crystal structure is broken. Generally speaking, in graphene there are several types of defects including point defect, such as Stone-Wales defects, vacancies, adatoms, substitutional impurities, topological defects, and one-dimensional defects, such as dislocation-like defects, defects at the edges of a graphene layer and defects in bilayer graphene [81]. Defects play significant parts in the formation of its mechanical properties. The mechanical properties can be improved and even engineered factitiously by introducing defects into graphene [82]. Here, as shown in Figure 8, we mainly talk about graphene with vacancies, dislocations and grain boundaries, the three typical types of defects.

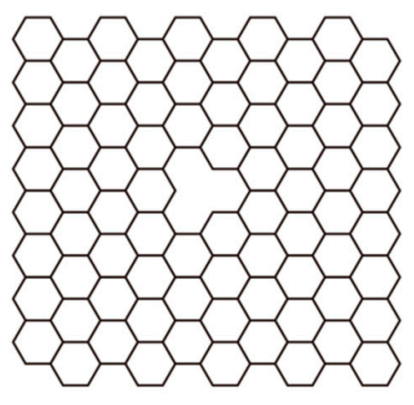

(a)

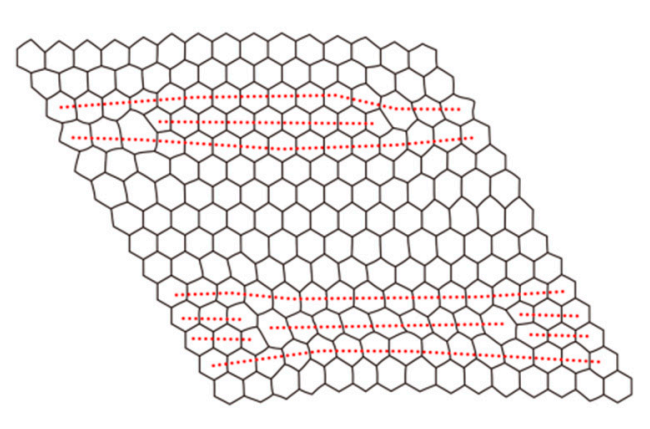

(b)

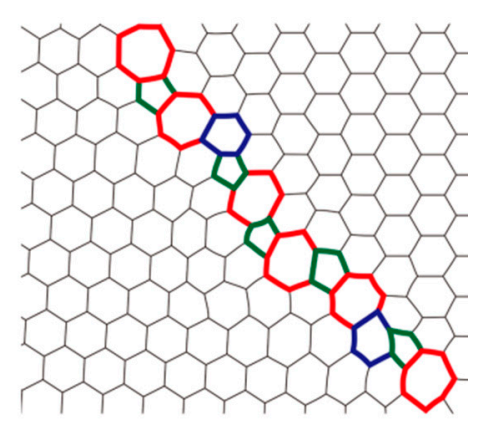

(c)

Figure 8. Schematic of defects in graphene: (a) Mono-vacancy; (b) Dislocations; (c) Grain Boundaries.

\subsection{Vacancies}

A representative configuration of vacancy is shown in Figure 8a. The deficiency of carbon atoms and cancellation of bonds can lead to such deformation of hexagon rings. The bombardment of high-energy particles such as electrons and ions can induce such atomic-scale defects on graphene [83].

Defect-free, monolayer graphene is considered to be the strongest material [1]. Zandiatashbar et al. [84] investigated how the inevitably existing defects affect the intrinsic strength and stiffness. An amazing discovery is that the stiffness and strength of graphene maintain even in the regime where $\mathrm{sp}^{3}$-type defects have higher densities with the breaking strength just $14 \%$ lower than that in pristine graphene [84]. However, the strength drops severely in the region of vacancy defects [84]. For polycrystalline CVD-grown graphene with various grain sizes, the elastic stiffness is the same as that of pristine graphene if post-processing steps avoid damage or rippling [85], which suggests that traditional CVD is a good method to produce graphene.

Vacancies can enhance the stiffness of graphene. A rather surprising result revealed that graphene with controlled defects introduced by irradiation performed higher 2D Young's modulus up to $700 \mathrm{~N} / \mathrm{m}$, and herein the authors pointed out that the increasing elastic modulus is related to the effects of thermal fluctuations [86]. Using molecular dynamics simulation, Kvashnin et al. [87] discovered that the stiffness of a monolayer graphene can be sufficiently enhanced by tiny-concentrated mono-vacancy 
defects, which meets experimental data [86] well and indicates that this phenomenon mainly results from how specific bonds distribute around monovacancy defects. However, this ability only belongs to monovacancies and other kinds of point defects, while other deficiencies such as Stone-Wales defects, are still unfavorable for the stiffness of graphene.

Vacancy-introduced graphene is put into wide use for chemical sensors [88]. The sensitiveness of graphene-based chemical sensors increased with the vacancies density rising, of which the mechanism was systematically investigated via experiments and Density Functional Theory (DFT) calculations, indicating that vacancies density is an increasing contributing factor to enhance sensitivity because of more charge transfer opportunities [88].

\subsection{Dislocations}

Dislocations are linear defects, around which the atoms of the crystal lattice are misaligned. There are two kinds of dislocations in graphene: screw and edge. An edge dislocation is shown in Figure $8 \mathrm{~b}$. Currently, a plastic deformation of materials can give birth to dislocations and causes their movement and propagation.

Not only dislocation density but also its behavior (such as movements) has a great influence on improving graphene mechanical performance. Warner et al. investigated the behavior of dislocations in graphene by tracking dislocation dynamics in real time [89]. They examined stepwise dislocation movement, which determined the strain fields, showing how dislocations deform graphene by compression of $\mathrm{C}-\mathrm{C}$ bonds, elongation, shear and lattice rotations.

The stability of dislocations dominates whether the properties caused by defects are stable. The first-principle DFT was used to study the stability of dislocations with pentagon-heptagon pairs in graphene layer, and the results showed that the structure of the dislocation defects with two pairs was more stable [90]. This study directed a way to engineer graphene with higher performances by introducing dislocation defects.

\subsection{Grain Boundaries}

A typical grain boundary is displayed in Figure 8c. A grain boundary is a linear arrangement of dislocations which produces a variety of non-hexagons at the boundary of graphene. Polymorphous graphene touches each other at the boundaries. Referring to the tilt between two inter-contact crystalline graphene, grain boundaries in polycrystalline graphene are categorized as low-angle (disorientation less than about $15^{\circ}$ ) and high-angle (disorientation greater than about $15^{\circ}$ ) grain boundaries. Counter to general intuition, an anomalous relation was revealed that high-angle graphene with high defects density possesses almost the same strength as pristine graphene, whereas low-angle graphene with low defects density exhibit a weaker strength [91]. Not only defects density but also the details of dislocations at grain boundaries play important roles in the rupture of graphene [92-94]. In addition, the distribution of dislocations is also an essential factor to dominate the fracture strength of grain boundaries [95]. A closer understanding of how the boundary affects mechanical performance will promote the use of CVD-synthesized graphene sheets in sensors, NEMS, and as pressure barriers.

Song et al. [93] built finite-grain-size models to carry out molecular dynamics simulations for the fracture of polycrystalline graphene. The results revealed that the strength of graphene reduced by over $50 \%$ because of the network of grain boundaries. Though larger grain size can enlarge Young's modulus, it will also decline tensile strength and failure strain drastically at the same time. The cracks are usually generated at the junctions.

\section{Strain and Defect Engineering: Electronic Properties of Graphene}

Because of large transparency [96], excellent electronic mobility [97], and high mechanical resilience, graphene shows great potentials in transparent flexible electronics, including foldable displays and transparent solar cells. The mechanical deformation of graphene have an effect on its electronic properties. The large elastic deformability of graphene enables a significant change in 
the lattice structure of the graphene, which offers tremendous opportunities to tailor the electronic properties of graphene through mechanical strain [98-101]. Guinea et al. acquired strong gauge fields that effectively played the part of a uniform magnetic field $(>10 \mathrm{~T})$ by inducing a designed strain aligned in the three main crystal directions and indicated that the significant energy gaps in graphene's electronic spectrum can be opened by strained superlattices [102].

As to whether the band gap in graphene can be opened by the strain, people hold different opinions. Gui et al. found that arbitrarily small uniaxial strains contributed to the opening of band gaps at Fermi level by using the first-principles calculations [99], while Farjam et al. held the opposite opinion [103]. Huang et al. showed that with the electronic transport measurement graphene has no band gap openings under moderate uniform strain [104]. Giulio et al. found a band gap could be varied from 0 to $0.9 \mathrm{eV}$ under a combination of shear and uniaxial strain with an arrangement from $12 \%$ to $17 \%$ [105]. Choi et al. studied that the strain had a great effect on electronic properties of graphene, and they come to a conclusion that the energy gap could not be generated from the strained graphene [106].

Compared to the band gap opening in monolayer graphene, the situation is more promising in the bilayer and tri-layer graphene. Verberck et al. used a perpendicular strain to open a band gap successfully in bilayer graphene, and more efficiently when two graphene layers are apart [107]. Meanwhile, Choi et al. had the similar findings [108]. Ramasubramaniam et al. tuned the band gaps from $0 \mathrm{eV}$ to $0.2 \mathrm{eV}$ in bilayer graphene [109].

For the defect engineering, extrinsic defects have a strong effect on the band structure of graphene and the electron interaction. Many interesting phenomena including spin-density waves, magnetism, charge- and spin-density waves, or Kondo effect can be produced by Transition metal atoms with dand f-electrons embedded into the graphene lattice [81]. Thus doping with metals, nitrogen, or boron seems to be an important issue for the design of graphene-based devices in nanoelectronics [110-112].

It has been reported that by defects from selectively adsorbing other atoms on surfaces or moving away some of carbon atoms from the graphene sheet, graphene can be transformed into a piezoelectric material though it is non piezoelectric intrinsically.

By DFT calculation, Ong et al. [113] discovered that if a sheet of monolayer graphene is doped with atoms on one side (such as $\mathrm{Li}, \mathrm{K}, \mathrm{H}, \mathrm{F}$ ) of both sides (such as $\mathrm{H}$ and F, F and Li), it will become piezoelectric. On one hand, an in-plane equibiaxial strain will be induced in the graphene sheet by an electric field vertical to the sheet. On the other hand, if the equibiaxial strain is applied on the sheet, the polarization of graphene vertical to the sheet will change. However, the strain mentioned here is very small, not larger than 0.01 . More research is required to understand what the piezoelectricity of graphene is like in larger range of strain.

By quantum mechanical calculations, Chandratre et al. [114] founded that graphene can be coaxed to be piezoelectric merely by making vacancy defects with right symmetry in the graphene sheet. And to obtain acquired piezoelectricity coefficient, one can change the shapes of porous areas, but the relationship between shapes of porous areas and piezoelectricity of defected graphene need to be further explored and expressed by a mathematical form. Note that the experiments for examining the piezoelectricity of defected graphene under these conditions are still rare, thus the applications will still be remote.

The study of the effect of defects on the electronic properties of graphene is still in development, and experimental data including the changes in electronic and optical characteristics and defect concentration are not sufficient to support research [111].

In summary, both the strain and defect engineering are appealing ways to modify the electrical properties, and precise controlling of the electronic structure is necessary in application of graphene.

\section{Strain and Defect Engineering: Optical Properties of Graphene}

When graphene has deformation or defects, its optical properties may change, including the optical conductivity, transparency, Raman spectrum and Rabi frequency [96,97,115-117]. For example, 
by adjusting the strain angle and modifying the strain tensor [112] (an example is presented in Figure 9), one can change the longitudinal optical conductivity, shown in Figure 10 [118]. The strain angle is the angle between the direction of strain and zigzag direction parallel to the long edge of this page. The strain and defect engineering make graphene have plenty of potential in the application of photo-detector, mode-locked lasers, photonics, plasmonics, optics, medical sensing and optical modulator [112].

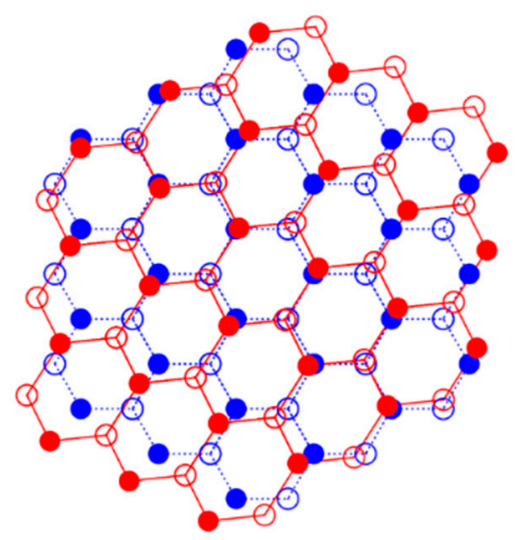

Figure 9. The red color shows the strained and the blue color presents the unstrained honeycomb lattice, where the value of strain angle is $\pi / 4$. Reprinted with permission from [118]. Copyright (2010) American Physical Society.

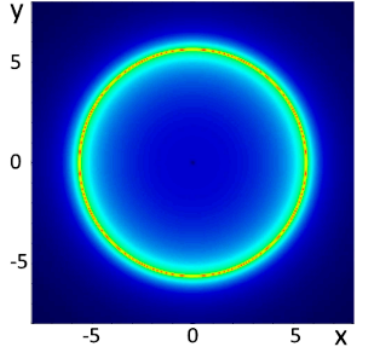

(a)

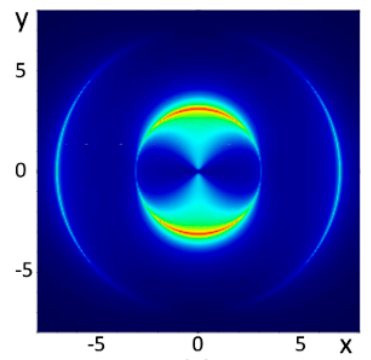

(c)

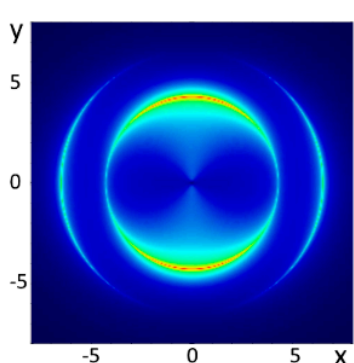

(b)

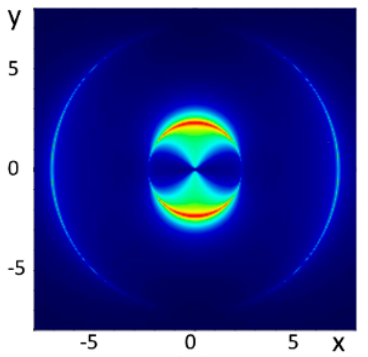

(d)

Figure 10. Longitudinal-optical conductivity. (a) Strain modulus $E=0$, the optical conductivity exhibits its maximum limit in the applied field angle; (b) The optical conductivity started splitting when strain modulus becomes non-zero $\left(E=0.075 \mathrm{~N} / \mathrm{m}^{2}\right)$; (c) Increased optical conductivity with the increased strain modulus $\left(E=0.175 \mathrm{~N} / \mathrm{m}^{2}\right)$; (d) Optical conductivity at $\mathrm{E}=0.275 \mathrm{~N} / \mathrm{m}^{2}$. Reprinted with permission from [118]. Copyright (2010) American Physical Society.

A time-ordered scattering model was used to explain the origin of $\mathrm{G}^{*}$-band $\approx 2450 \mathrm{~cm}^{-1}$ in the Raman spectrum of graphene [117]. The intensity of the $G^{*}$-band showed to be sensitive to the concentration of defects. This means that the defect configuration and its local environment, rather than number of defects present in graphene, are critical for time-ordered carrier scattering processes. 
The absorption energy of pristine graphene and defective graphene has been studied by Yan et al., shown in Figure 11 [119]. On the pristine graphene surface, the adsorption energy of germanium atoms in different positions is very small, while for the vacancy-defected graphene case, the larger adsorption energy shows that the defect core induces a more stable interaction with the gallium adatom, which indicates that the vacancy-defected graphene has higher stability with the gallium adatoms than the original graphene.

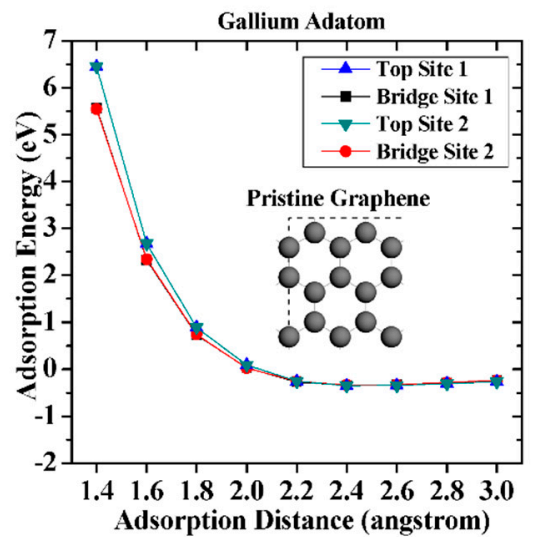

(a)

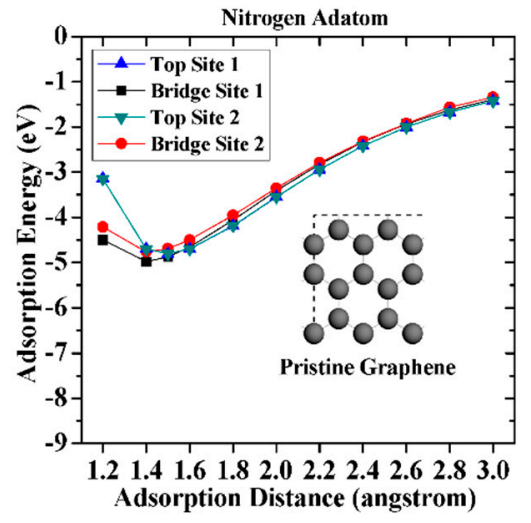

(c)

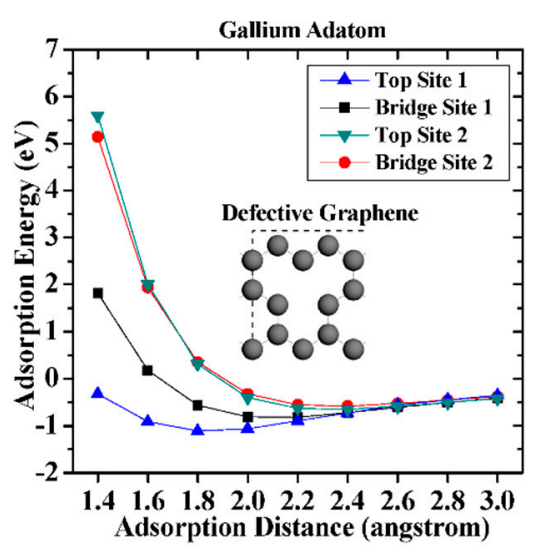

(b)

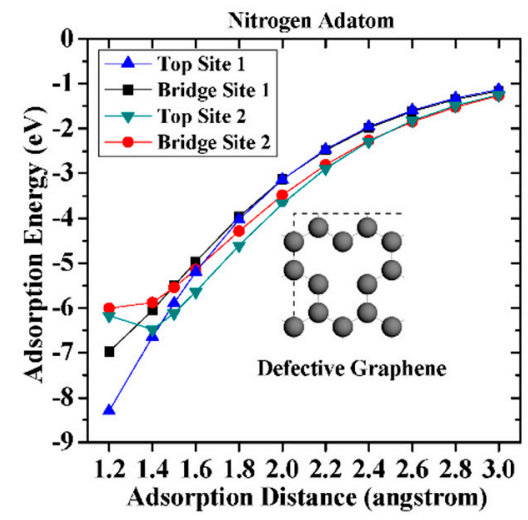

(d)

Figure 11. Adsorption energy curves of (a) the gallium adatom on pristine graphene; (b) the gallium atom on vacancy-defected graphene vacancy-defected graphene; (c) the nitrogen atom on pristine graphene; and (d) the nitrogen atom on vacancy-defected graphene. Reprinted (adapted) with permission from [119].

\section{Temperature Effect on Mechanical Properties of Graphene}

Temperature can have an influence on the performance of graphene and its composites [120-122]. MD simulations have been carried out to discuss the influence of temperature on the mechanical properties of graphene under uniaxial tensile loading, and it has been found that the fracture stress and strain change approximately linearly with temperature [123]. Due to the fracture stress, the increase in temperature turns graphene to be weaker and thus Young's modulus decreases. As can be seen in Figure 12b [124], Young's modulus decreases monotonically with temperature, showing that temperature has an adverse effect on the mechanical properties [123]. 


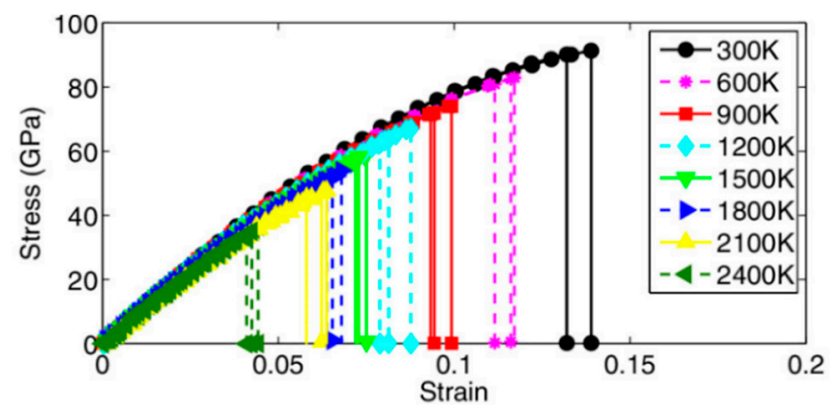

(a)

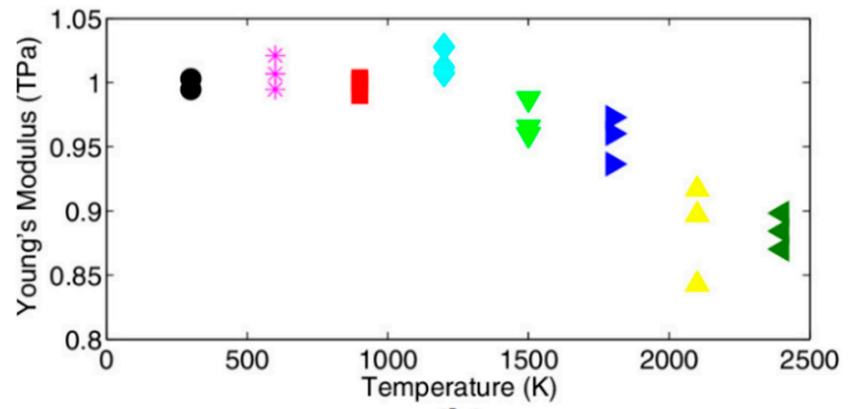

(b)

Figure 12. (a) The stress-strain curve of graphene tested by uniaxial tensile stress along the armchair direction at different temperatures; (b) Young's moduli of graphene in (a). Reprinted (adapted) with permission from [124]. Copyright (2010) AIP Publishing.

Although the basic elastic properties of graphene have been reasonably understood according to the first principle, there is not enough knowledge about the effects of finite temperature on the elastic properties. It is known to all that monolayer graphene sheets are not completely flat at a limited temperature. ( $\mathrm{T}>0 \mathrm{~K})$. Theoretically, thermal rippling is unavoidable [125], which may have a great influence on thermo-mechanical properties of graphene [126], such as temperature-dependent elastic modulus and thermal expansion. One manifestation of thermal rippling is that Zhao et al. [124] found that Young's modulus does not vary significantly with temperature until about $1200 \mathrm{~K}$, beyond which the material becomes softer. The other is the reduction of the projected area, which is considered to be the reason for the negative in-plane thermal expansion of graphene [8]. In addition to graphene, thermal ripple effects are equally important for other 2D materials due to low bending stiffness, although experimental evidence of this effect is limited.

\section{Mechanical Properties of Graphene Derivatives}

\subsection{Graphane}

When all carbon atoms of graphene are hydrogenated, as shown in Figure 13, the graphene sheet turns to be graphane. Graphane has been successfully synthesized, and some methods were reported by Qing Peng et al. [127], such as annealing [120], and thermal exfoliation [128]. The mechanical response of graphane has been studied by DFT simulation, indicating that graphane is anisotropic when deforming along armchair, zigzag and biaxial directions [121,123-129]. Graphane has a stiffness of $242 \mathrm{Nm}^{-1}$ [127], which is about 2/3 that of graphene. So it is much softer than graphene. Furthermore, graphane possesses the smaller Poisson's ratio among monolayer honeycomb structures [129]. 


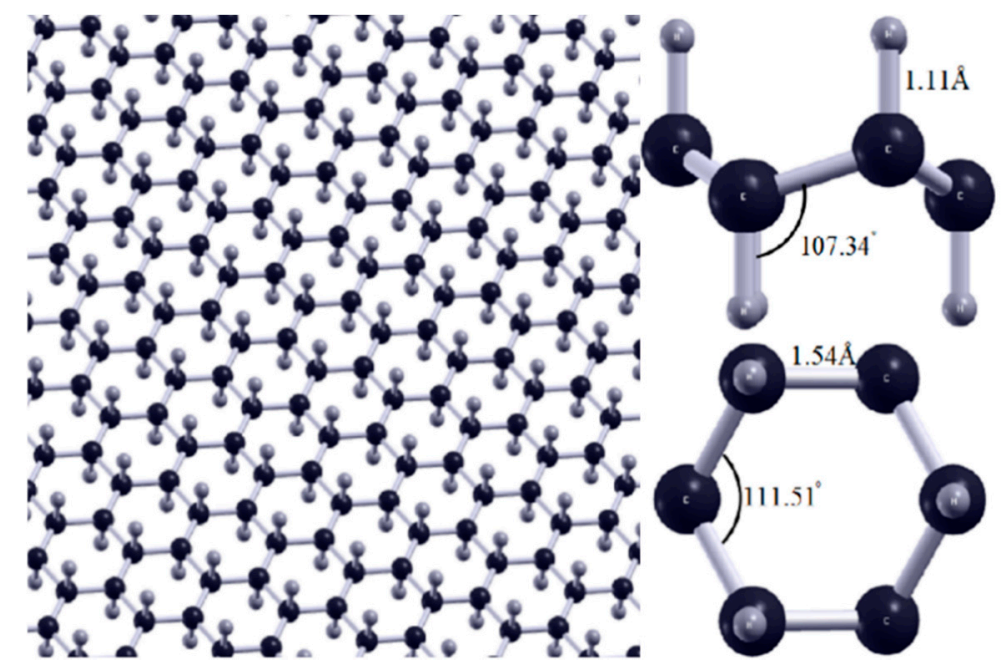

Figure 13. Geometry of graphane. Left: graphane plane. Right: graphane molecule in different views. Reproduced from [129] with permission from the PCCP Owner Societies.

Based on different properties from graphene, there are many potential applications for graphane [127], such as hydrogen storage, biosensing and spintropics. The novel graphane biosensing devices are based on experimental investigations of Tan et al. [130-135]. In addition, the applications for spintropics devices have been examined both experimentally and theoretically [135].

\subsection{Graphone}

When only half carbon atoms are hydrogenated, and those hydrogen atoms only occupy one side of the graphene sheet, as shown in Figure 14, the graphene sheet turns to be graphone. According to the examination of graphone by molecular dynamics simulations [130], graphone is known to be a stable structure at room temperature. Unfortunately, due to the rigid atomic structure, the synthesis of graphone meets a lot of difficulties [131]. Despite of the unsolved synthesis of graphone, the applications are fascinating, which attract a lot of efforts from the worldwide institutions. Graphone is proved to be a possible material for Field Effect Transistors [132] and has potential applications in cases where organic ferroelectric is required [133].

(a)

(c)

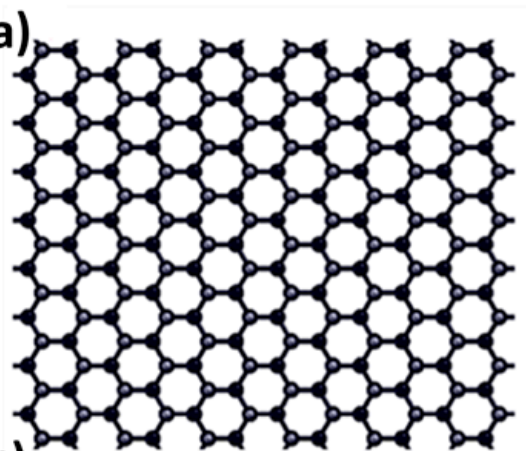

(b)
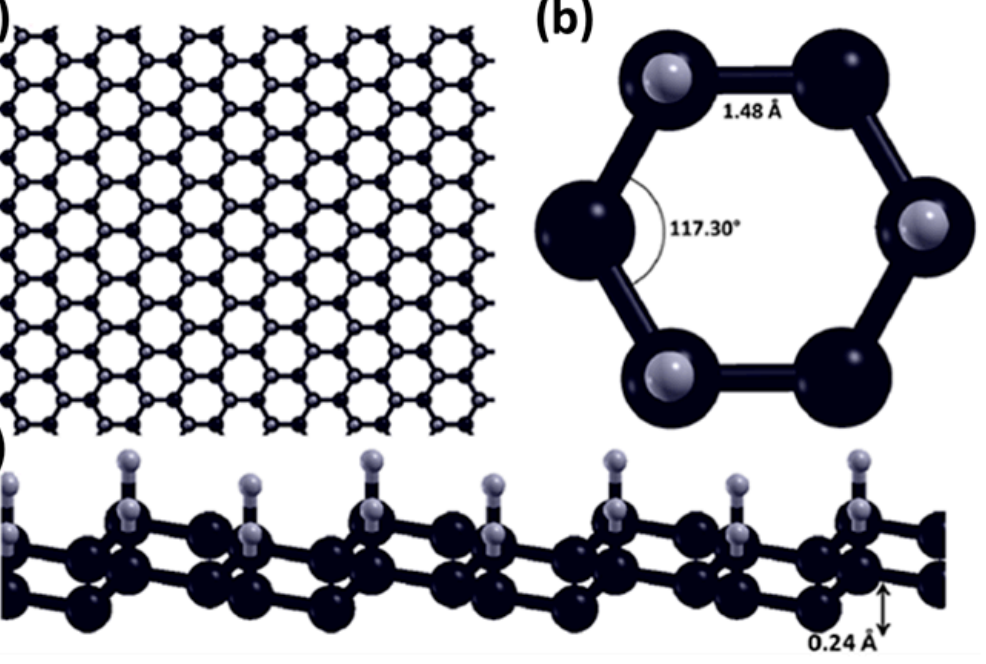

Figure 14. (a) Graphone plane; (b) Overview and (c) side-view of graphone. 


\subsection{Graphyne}

Graphyne is an allotrope of graphene. Graphyne is a monolayer with only sp and $\mathrm{sp}^{2}$ bonded carbon atoms arranging in lattice, which is synthesized only in the form of fragments [136,137]. There is a variety of graphynes due to various arrangements of double and triple bonds [138], shown in Figure 15.

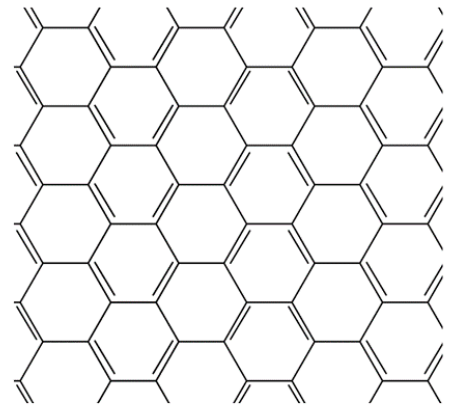

(a)

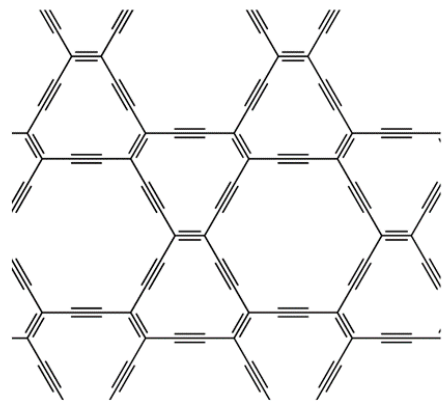

(c)

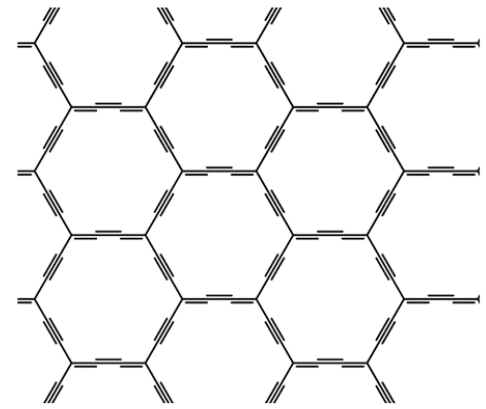

(b)

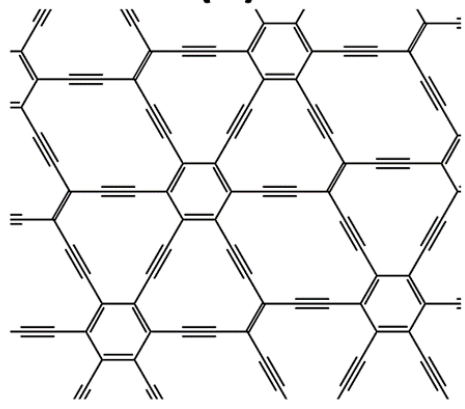

(d)

Figure 15. Structures of graphene and graphynes. (a) Graphene; (b) $\alpha$-graphyne; (c) $\beta$-graphyne; (d) 6,6,12-graphyne (or $\delta$-graphyne).

Mechanical properties of graphyne are studied both in infinite sheets and nanoscale flakes. In order to construct a stable configuration, the edges of finite graphyne flakes were hydrogenated to satisfy the dangling bonds. In this configuration, the ultimate stress is found to be $48.2 \mathrm{GPa}$ for the armchair direction, and $107.5 \mathrm{GPa}$ in the zigzag direction, with corresponding stiffnesses of 532.5 and 700 GPa [139-141].

Although graphyne has yet to be well synthesized, its mechanical properties show strong promise for several applications, such as nanofillers [142], transistors, sensors [139], semiconductor-metal hybrids [139], and anisotropic conductors [142].

\subsection{Fluorographene}

Fluorographene is the structure of fully or partially fluorinated graphene. Fluorination and exfoliation are two dominating kinds of methods for producing fluorographene [143-146]. As a nanoscale 2D material, the edge effect is significant including its energy and stress. A lot of investigations on fluorographene focus on the edge-related mechanical properties.

By applying ab initio simulations, Feng et al. have chosen four types of fluorographene nanoribbons, and have studied their edge-based mechanical properties [147]. They discovered that when the width of ribbons goes beyond $10 \AA$, the edge energy quickly climbs up to a high level and then grows slowly at a very small rate. What's more, the edge stresses are influenced by the width of fluorographene nanoribbons, and are smaller than those in graphene nanoribbons $[148,149]$. 
Fluorographene has many important potential applications like its family members. By integrating chemical groups, polymer chains and functional nanoparticles, fluorographene and its composites will be useful in secondary batteries, such as $\mathrm{Li}, \mathrm{Na}$ and Li-S battery. They can also be used as super-insulating materials, light emitting diodes (LED) and display materials. And with well-controlled structures and mechanical properties, fluorographene seems hopefully to be an excellent material in special protective coatings, energy processing and tissue engineering [146].

\subsection{Graphene Oxide}

Graphene oxide (GO), including reduced graphene oxide (RGO) and thermally reduced GO (TRGO), is typical graphene materials with topological defects in their periodic structures $[150,151]$, shown in Figure 16. GO exhibited an extra Raman peak below the $G$ band (about $1600 \mathrm{~cm}^{-1}$ ) in Figure 16b, which was ascribed to the oxidation of graphite and the subsequent introduction of defects in the graphitic planes. It could be seen in Figure 16c,d that the graphene sheets were folded, which is probably due to high Van der Waals attraction [150].

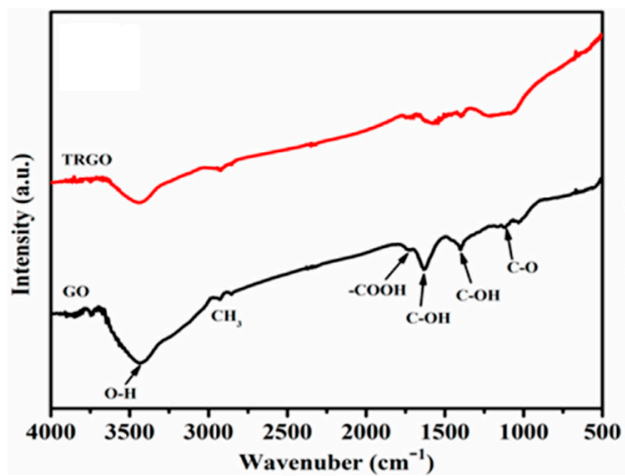

(a)

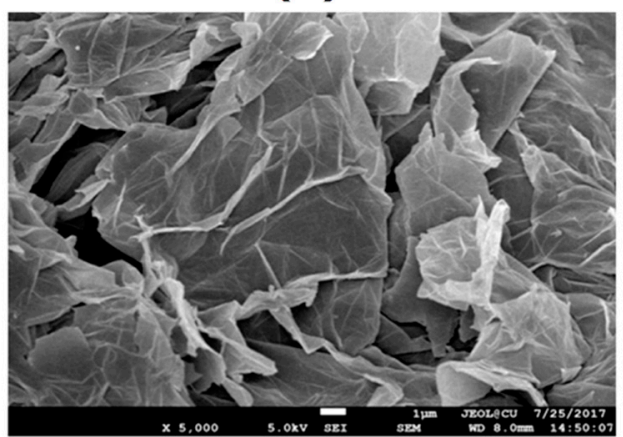

(c)

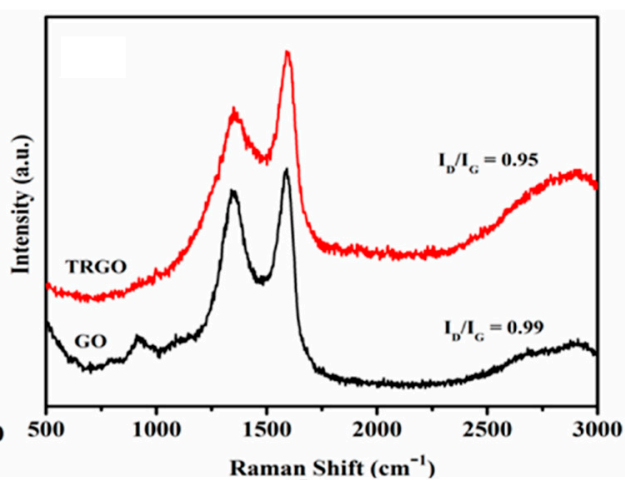

(b)

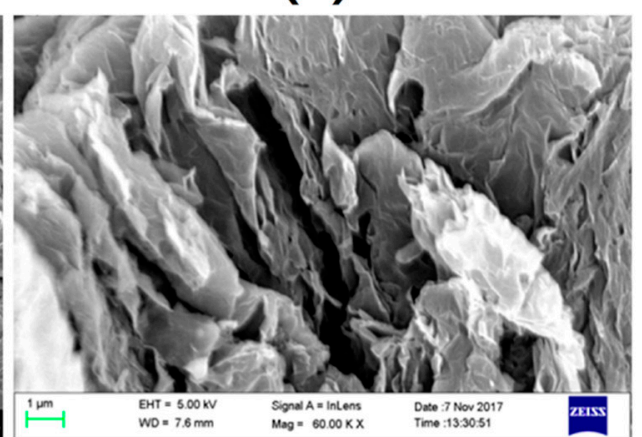

(d)

Figure 16. (a) Fourier transform infrared spectroscopy (FTIR) and (b) Raman spectra and FE-SEM image of (c) GO and (d) TRGO. Reprinted (adapted) with the permission from [150].

The mechanical properties of GO were first reported by Dikin et al. [152]. The stress distribution across the material was homogeneous and the stiffness was found to be up to $40 \mathrm{GPa}$, while the strength was only $120 \mathrm{MPa}$. Xiang et al. produced graphene oxide fibers, whose stiffness is high up to $0.5 \mathrm{GPa}$ [153]. However, recent researches only detected poorer or comparable values of strength, while some measured comparable enhancement of Young's modulus. The formation, characteristics, and properties of graphene oxide fibers (and hybrid graphene oxide fibers) had extensive research and impressive work on them. These materials were found to be fitting for applications such as supercapacitors, desalination, functional fabrics, stretchable conductors and aerogels amongst others $[137,150,154]$. 


\section{Conclusions and Outlook}

Graphene is one of the most important materials with extraordinary properties due to the unique atom-thick honeycomb-like 2D carbon crystalline structure with quantum confinement. As a consequence, tremendous applications, such as graphene composites, nano-switches [155], resonators [156], and even motors [157], were developed based on its outstanding mechanical properties. In this paper, firstly, several main perspectives including tension and compression, fracture, shearing, bending, friction, and dynamics properties of graphene are reviewed. It can be noticed that the research for elastic properties of graphene under shear loads and dynamics properties are still lack of the support from experiments. The basis of graphene mechanics is not stable. Then, the mechanical properties of bilayer and multilayer graphene are also reviewed, revealing that the mechanism of the change of mechanical properties caused by increasing graphene layers is still vague. Further, strain engineering and defects are introduced as an effective way to modify the mechanical properties, electronic structure, and optical properties of graphene. The problem left for the industrial world is how to manipulate the strain and defect in graphene accurately and effectively with low cost. Temperature effect is then discussed, and should be an important factor to be considered in manufacturing. As the new members of graphene family, graphane, graphone, graphyne, fluorographene, and graphene oxide are reviewed too, and some extraordinary mechanical properties are revealed. Although graphene and its family members are proved to be promising material in many aspects, there is still a long way for practical use. Taking into account of those attractive mechanical properties, promising applications are reinforcement, coatings, strain sensors, biomedicine, and transparent conducting films for flexible electronics. Our review also shows that extensive efforts are needed from both experimental and theoretical aspects for comprehensive understanding of graphene mechanics.

Author Contributions: Q.C. and Q.P. conceived the idea of the paper. Q.C., X.G., H.W., P.W. and A.L. wrote the paper. Y.L. and Q.C. did experimental investigations on graphene. All the authors had a full discussion and comment on the paper.

Funding: This research was funded by the National Natural Science Foundation of China (No. 51727901).

Acknowledgments: We want to acknowledge Shuting Lei, Yang Yang, Yudong Rong, Jian Zhou, Qiao Lin, Pinxuan He, Qi Li and Wei Ye for their discussions and helpful support.

Conflicts of Interest: The authors declare no conflict of interest.

\section{References}

1. Lee, C.; Wei, X.D.; Kysar, J.W.; Hone, J. Measurement of the elastic properties and intrinsic strength of monolayer graphene. Science 2008, 321, 385-388. [CrossRef] [PubMed]

2. Pavol Lengvarský, J.B. Prediction of young's modulus of graphene sheets by the finite element method. Am. J. Mech. Eng. 2015, 3, 225-229.

3. Yeh, Y.K.; Hwu, C. A modified molecular-continuum model for estimating the strength and fracture toughness of graphene and carbon nanotube. Eng. Fract. Mech. 2017, 176, 326-342. [CrossRef]

4. Rasool, H.I.; Ophus, C.; Klug, W.S.; Zettl, A.; Gimzewski, J.K. Measurement of the intrinsic strength of crystalline and polycrystalline graphene. Nat. Commun. 2013, 4, 2811. [CrossRef]

5. Zhang, P.; Ma, L.L.; Fan, F.F.; Zeng, Z.; Peng, C.; Loya, P.E.; Liu, Z.; Gong, Y.J.; Zhang, J.N.; Zhang, X.X.; et al. Fracture toughness of graphene. Nat. Commun. 2014, 5, 3782. [CrossRef] [PubMed]

6. Kudin, K.N.; Scuseria, G.E.; Yakobson, B.I. C2f, BN, and C nanoshell elasticity from ab initio computations. Phys. Rev. B 2001, 64, 235406.

7. Liu, F.; Ming, P.M.; Li, J. Ab initio calculation of ideal strength and phonon instability of graphene under tension. Phys. Rev. B 2007, 76, 064120. [CrossRef]

8. Zakharchenko, K.V.; Katsnelson, M.I.; Fasolino, A. Finite temperature lattice properties of graphene beyond the quasiharmonic approximation. Phys. Rev. Lett. 2009, 102, 046808. [CrossRef] [PubMed] 
9. Guo, J.G.; Zhou, L.J.; Kang, Y.L. Chirality-dependent anisotropic elastic properties of a monolayer graphene nanosheet. J. Nanosci. Nanotechnol. 2012, 12, 3159-3164. [CrossRef] [PubMed]

10. Kalosakas, G.; Lathiotakis, N.N.; Galiotis, C.; Papagelis, K. In-plane force fields and elastic properties of graphene. J. Appl. Phys. 2013, 113, 134307. [CrossRef]

11. Wei, D.; Song, Y.; Wang, F. A simple molecular mechanics potential for $\mu \mathrm{m}$ scale graphene simulations from the adaptive force matching method. J. Chem. Phys. 2011, 134, 184704. [CrossRef] [PubMed]

12. Zhao, H.; Min, K.; Aluru, N.R. Size and chirality dependent elastic properties of graphene nanoribbons under uniaxial tension. Nano Lett. 2009, 9, 3012. [CrossRef] [PubMed]

13. Wang, W. Study on Mechanical Properties and Variable-Temperature Raman Spectral Characteristics of Graphene-Substrate System. Ph.D. Thesis, Huazhong University of Science and Technology, Wuhan, China, 2016.

14. Zhang, B.; Mei, L.; Xiao, H.F. Nanofracture in graphene under complex mechanical stresses. Appl. Phys. Lett. 2012, 101, 121915. [CrossRef]

15. Sakhaee-Pour, A. Elastic properties of single-layered graphene sheet. Solid State Commun. 2009, 149, 91-95. [CrossRef]

16. Liu, X.; Metcalf, T.H.; Robinson, J.T.; Houston, B.H.; Scarpa, F. Shear modulus of monolayer graphene prepared by chemical vapor deposition. Nano Lett. 2012, 12, 1013-1017. [CrossRef] [PubMed]

17. Wei, Y.J.; Wang, B.L.; Wu, J.T.; Yang, R.G.; Dunn, M.L. Bending rigidity and gaussian bending stiffness of single-layered graphene. Nano Lett. 2013, 13, 26-30. [CrossRef] [PubMed]

18. Ragab, T.; McDonald, J.; Basaran, C. Aspect ratio effect on shear modulus and ultimate shear strength of graphene nanoribbons. Diam. Relat. Mater. 2017, 74, 9-15. [CrossRef]

19. Min, K.; Aluru, N.R. Mechanical properties of graphene under shear deformation. Appl. Phys. Lett. 2011, 98, 013113. [CrossRef]

20. Wang, Q. Simulations of the bending rigidity of graphene. Phys. Lett. A 2010, 374, 1180-1183. [CrossRef]

21. Los, J.H.; Fasolino, A.; Katsnelson, M.I. Scaling behavior and strain dependence of in-plane elastic properties of graphene. Phys. Rev. Lett. 2016, 116, 015901. [CrossRef] [PubMed]

22. Jiang, J.W.; Chang, T.; Guo, X.; Park, H.S. Intrinsic negative poisson's ratio for single-layer graphene. Nano Lett. 2016, 16, 5286. [CrossRef] [PubMed]

23. Jiang, J.W.; Park, H.S. Negative poisson's ratio in single-layer graphene ribbons. Nano Lett. 2016, 16, 2657. [CrossRef] [PubMed]

24. Deng, B.; Hou, J.; Zhu, H.; Liu, S.; Liu, E.; Shi, Y.; Peng, Q. The normal-auxeticity mechanical phase transition in graphene. 2D Mater. 2017, 4, 021020. [CrossRef]

25. Androulidakis, C.; Tsoukleri, G.; Koutroumanis, N.; Gkikas, G.; Pappas, P.; Parthenios, J.; Papagelis, K.; Galiotis, C. Experimentally derived axial stress-strain relations for two-dimensional materials such as monolayer graphene. Carbon 2015, 81, 322-328. [CrossRef]

26. Tsoukleri, G.; Parthenios, J.; Papagelis, K.; Jalil, R.; Ferrari, A.C.; Geim, A.K.; Novoselov, K.S.; Galiotis, C. Subjecting a graphene monolayer to tension and compression. Small 2009, 5, 2397-2402. [CrossRef] [PubMed]

27. Pradhan, S.C. Buckling of single layer graphene sheet based on nonlocal elasticity and higher order shear deformation theory. Phys. Lett. A 2009, 373, 4182-4188. [CrossRef]

28. Pradhan, S.C.; Murmu, T. Small scale effect on the buckling of single-layered graphene sheets under biaxial compression via nonlocal continuum mechanics. Comput. Mater. Sci. 2009, 47, 268-274. [CrossRef]

29. Civalek, O. Elastic buckling behavior of skew shaped single-layer graphene sheets. Thin Solid Films 2014, 550, 450-458. [CrossRef]

30. Ashino, M.; Wiesendanger, R. Atomic-site-specific analysis on out-of-plane elasticity of convexly curved graphene and its relationship to $\mathrm{sp}(2)$ to $\mathrm{sp}(3)$ re-hybridization. Crystals 2018, 8, 102. [CrossRef]

31. Lawn, B. Fracture of Brittle Solids; Cambridge University Press: Cambridge, UK, 1993.

32. Moura, M.J.; Marder, M. Tearing of free-standing graphene. Phys. Rev. E Stat. Nonlinear Soft Matter Phys. 2013, 88, 032405. [CrossRef] [PubMed]

33. Annett, J.; Cross, G.L.W. Self-assembly of graphene ribbons by spontaneous self-tearing and peeling from a substrate. Nature 2016, 535, 271-275. [CrossRef] [PubMed]

34. Han, J.; Ryu, S.; Sohn, D. A feasibility study on the fracture strength measurement of polycrystalline graphene using nanoindentation with a cylindrical indenter. Carbon 2016, 107, 310-318. [CrossRef]

35. Tsai, J.L.; Tu, J.F. Characterizing mechanical properties of graphite using molecular dynamics simulation. Mater. Des. 2010, 31, 194-199. [CrossRef] 
36. Scarpa, F.; Adhikari, S.; Chowdhury, R. The transverse elasticity of bilayer graphene. Phys. Lett. A 2010, 374, 2053-2057. [CrossRef]

37. Shen, Y.K.; Wu, H.A. Interlayer shear effect on multilayer graphene subjected to bending. Appl. Phys. Lett. 2012, 100, 101909. [CrossRef]

38. Zhang, H.; Guo, Z.; Gao, H.; Chang, T. Stiffness-dependent interlayer friction of graphene. Carbon 2015, 94, 60-66. [CrossRef]

39. Cheng, Y.; Zhu, P.Z.; Li, R. The influence of vertical vibration on nanoscale friction: A molecular dynamics simulation study. Crystals 2018, 8, 129. [CrossRef]

40. Li, R.; Song, C.G. The influence of hydroxyl groups on friction of graphene at atomic scale. Crystals 2018, 8, 167.

41. Sakhaee-Pour, A.; Ahmadian, M.T.; Naghdabadi, R. Vibrational analysis of single-layered graphene sheets. Nanotechnology 2008, 19, 085702. [CrossRef] [PubMed]

42. Tserpes, K.I.; Papanikos, P. Finite element modeling of single-walled carbon nanotubes. Compos. Part B 2005, 36, 468-477. [CrossRef]

43. Li, C.; Chou, T.W. A structural mechanics approach for the analysis of carbon nanotubes. Int. J. Solids Struct. 2003, 40, 2487-2499. [CrossRef]

44. Hashemnia, K.; Farid, M.; Vatankhah, R. Vibrational analysis of carbon nanotubes and graphene sheets using molecular structural mechanics approach. Comput. Mater. Sci. 2009, 47, 79-85. [CrossRef]

45. Sadeghi, M.; Naghdabadi, R. Nonlinear vibrational analysis of single-layer graphene sheets. Nanotechnology 2010, 21, 105705. [CrossRef] [PubMed]

46. Gupta, S.S.; Batra, R.C. Elastic properties and frequencies of free vibrations of single-layer graphene sheets. J. Comput. Theor. Nanosci. 2010, 7, 2151-2164. [CrossRef]

47. Ansari, R.; Sahmani, S.; Arash, B. Nonlocal plate model for free vibrations of single-layered graphene sheets. Phys. Lett. A 2010, 375, 53-62. [CrossRef]

48. Scarpa, F.; Chowdhury, R.; Kam, K.; Adhikari, S.; Ruzzene, M. Dynamics of mechanical waves in periodic graphene nanoribbon assemblies. Nanoscale Res. Lett. 2011, 6, 1-10. [CrossRef] [PubMed]

49. Mianroodi, J.R.; Niaki, S.A.; Naghdabadi, R.; Asghari, M. Nonlinear membrane model for large amplitude vibration of single layer graphene sheets. Nanotechnology 2011, 22, 305703. [CrossRef] [PubMed]

50. Chowdhury, R.; Adhikari, S.; Scarpa, F.; Friswell, M.I. Transverse vibration of single-layer graphene sheets. J. Phys. D Appl. Phys. 2011, 44, 205401-205411. [CrossRef]

51. Akgöz, B.; Civalek, Ö. Free vibration analysis for single-layered graphene sheets in an elastic matrix via modified couple stress theory. Mater. Des. 2012, 42, 164-171. [CrossRef]

52. Baykasoglu, C.; Mugan, A. Dynamic analysis of single-layer graphene sheets. Comput. Mater. Sci. 2012, 55, 228-236. [CrossRef]

53. Alyokhin, V.V.; Annin, B.D.; Babichev, A.V.; Korobeynikov, S.N. Free vibrations and buckling of graphene sheets. Mech. Solids 2013, 58, 487-490. [CrossRef]

54. Mirparizi, M.; Aski, F.S. Interlayer shear effect on vibrational behavior of bilayer graphene using the molecular mechanics simulation. Propuls. Power Res. 2016, 5, 250-260. [CrossRef]

55. Jang, B.; Mag-isa, A.E.; Kim, J.-H.; Kim, B.; Lee, H.-J.; Oh, C.-S.; Sumigawa, T.; Kitamura, T. Uniaxial fracture test of freestanding pristine graphene using in situ tensile tester under scanning electron microscope. Extreme Mech. Lett. 2017, 14, 10-15. [CrossRef]

56. Li, C.; Chou, T.W. Elastic moduli of multi-walled carbon nanotubes and the effect of van der waals forces. Compos. Sci. Technol. 2003, 63, 1517-1524. [CrossRef]

57. Cho, J.; Luo, J.J.; Daniel, I.M. Mechanical characterization of graphite/epoxy nanocomposites by multi-scale analysis. Compos. Sci. Technol. 2007, 67, 2399-2407. [CrossRef]

58. Wang, G.R.; Dai, Z.H.; Wang, Y.L.; Tan, P.H.; Liu, L.Q.; Xu, Z.P.; Wei, Y.G.; Huang, R.; Zhang, Z. Measuring interlayer shear stress in bilayer graphene. Phys. Rev. Lett. 2017, 119, 036101. [CrossRef] [PubMed]

59. Neek-Amal, M.; Peeters, F.M. Nanoindentation of a circular sheet of bilayer graphene. Phys. Rev. B 2010, 81, 235421. [CrossRef]

60. Kordkheili, S.A.H.; Moshrefzadeh-Sani, H. Mechanical properties of double-layered graphene sheets. Comput. Mater. Sci. 2013, 69, 335-343. [CrossRef]

61. Zhang, J.F.; Zhao, J.J. Mechanical properties of bilayer graphene with twist and grain boundaries. J. Appl. Phys. 2013, 113, 043514. [CrossRef] 
62. Zhang, Y.Y.; Wang, C.M.; Cheng, Y.; Xiang, Y. Mechanical properties of bilayer graphene sheets coupled by sp(3) bonding. Carbon 2011, 49, 4511-4517. [CrossRef]

63. Yin, H.; Qi, H.J.; Fan, F.; Zhu, T.; Wang, B.; Wei, Y. Griffith criterion for brittle fracture in graphene. Nano Lett. 2015, 15, 1918-1924. [CrossRef] [PubMed]

64. Datta, D.; Nadimpalli, S.P.V.; Li, Y.; Shenoy, V.B. Effect of crack length and orientation on the mixed-mode fracture behavior of graphene. Extreme Mech. Lett. 2015, 5, 10-17. [CrossRef]

65. Muniz, A.R.; Machado, A.S.; Maroudas, D. Mechanical behavior of interlayer-bonded nanostructures obtained from bilayer graphene. Carbon 2015, 81, 663-677. [CrossRef]

66. Wang, L.; Zhang, Q. Elastic behavior of bilayer graphene under in-plane loadings. Curr. Appl. Phys. 2012, 12, 1173-1177. [CrossRef]

67. Chandra, Y.; Chowdhury, R.; Adhikari, S.; Scarpa, F. Elastic instability of bilayer graphene using atomistic finite element. Phys. E 2011, 44, 12-16. [CrossRef]

68. Chandra, Y.; Chowdhury, R.; Scarpa, F.; Adhikaricor, S. Vibrational characteristics of bilayer graphene sheets. Thin Solid Films 2011, 519, 6026-6032. [CrossRef]

69. Nazemnezhad, R.; Kamali, K.; Hosseini-Hashemi, S. Study on tensile-compressive and shear effects of van der waals interactions on free vibration of bilayer graphene nanoribbons. Meccanica 2016, 52, 1-20. [CrossRef]

70. Wang, K.F.; Wang, B.L.; Zeng, S. Small scale effect on the pull-in instability and vibration of graphene sheets. Microsyst. Technol. 2017, 23, 2033-2041. [CrossRef]

71. Zhang, Y.; Zhang, L.W.; Liew, K.M.; Yu, J.L. Free vibration analysis of bilayer graphene sheets subjected to in-plane magnetic fields. Compos. Struct. 2016, 144, 86-95. [CrossRef]

72. Wu, Z.T.; Hu, F.Y.; Zhang, Y.; Gao, Q.; Chen, Z.P. Mechanical analysis of double-layered circular graphene sheets as building material embedded in an elastic medium. J. Cent. South Univ. 2017, 24, 2717-2724. [CrossRef]

73. Wu, Z.T.; Zhang, Y.; Hu, F.Y.; Gao, Q.; Xu, X.Y.; Zheng, R.H. Vibration analysis of bilayered graphene sheets for building materials in thermal environments based on the element-free method. J. Nanomater. 2018, 2018, 6508061. [CrossRef]

74. Cranford, S.; Buehler, M.J. Twisted and coiled ultralong multilayer graphene ribbons. Model. Simul. Mater. Sci. Eng. 2011, 19, 054003. [CrossRef]

75. Yang, L.; Guo, Y.J.; Zhang, Q. Frictional behavior of strained multilayer graphene: Tuning the atomic scale contact area. Diam. Relat. Mater. 2017, 73, 273-277. [CrossRef]

76. Wang, J.; He, X.; Kitipornchai, S.; Zhang, H. Geometrical nonlinear free vibration of multi-layered graphene sheets. J. Phys. D Appl. Phys. 2011, 44, 135401. [CrossRef]

77. Jomehzadeh, E.; Saidi, A.R. A study on large amplitude vibration of multilayered graphene sheets. Comput. Mater. Sci. 2011, 50, 1043-1051. [CrossRef]

78. Lu, L.; Ru, C.Q.; Guo, X.M. Vibration of a multilayer graphene sheet under layerwise tension forces. Int. J. Mech. Sci. 2017, 121, 157-163. [CrossRef]

79. Bunch, J.S.; van der Zande, A.M.; Verbridge, S.S.; Frank, I.W.; Tanenbaum, D.M.; Parpia, J.M.; Craighead, H.G.; McEuen, P.L. Electromechanical resonators from graphene sheets. Science 2007, 315, 490-493. [CrossRef] [PubMed]

80. Garcia-Sanchez, D.; van der Zande, A.M.; Paulo, A.S.; Lassagne, B.; McEuen, P.L.; Bachtold, A. Imaging mechanical vibrations in suspended graphene sheets. Nano Lett. 2008, 8, 1399-1403. [CrossRef] [PubMed]

81. Banhart, F.; Kotakoski, J.; Krasheninnikov, A.V. Structural defects in graphene. ACS Nano 2011, 5, $26-41$. [CrossRef] [PubMed]

82. Amorim, R.G.; Fazzio, A.; Antonelli, A.; Novaes, F.D.; da Silva, A.J.R. Divacancies in graphene and carbon nanotubes. Nano Lett. 2007, 7, 2459-2462. [CrossRef] [PubMed]

83. Lehtinen, O.; Kotakoski, J.; Krasheninnikov, A.V.; Tolvanen, A.; Nordlund, K.; Keinonen, J. Effects of ion bombardment on a two-dimensional target: Atomistic simulations of graphene irradiation. Phys. Rev. B 2010, 81, 153401. [CrossRef]

84. Zandiatashbar, A.; Lee, G.H.; An, S.J.; Lee, S.; Mathew, N.; Terrones, M.; Hayashi, T.; Picu, C.R.; Hone, J.; Koratkar, N. Effect of defects on the intrinsic strength and stiffness of graphene. Nat. Commun. 2014, 5, 3186. [CrossRef] [PubMed] 
85. Lee, G.H.; Cooper, R.C.; An, S.J.; Lee, S.; Van, D.Z.A.; Petrone, N.; Hammerberg, A.G.; Lee, C.; Crawford, B.; Oliver, W. High-strength chemical-vapor-deposited graphene and grain boundaries. Science 2013, 340, 1073-1076. [CrossRef] [PubMed]

86. López-Polín, G.; Gómez-Navarro, C.; Parente, V.; Guinea, F.; Katsnelson, M.I.; Pérez-Murano, F.; Gómez-Herrero, J. Increasing the elastic modulus of graphene by controlled defect creation. Nat. Phys. 2014, 11, 26-31. [CrossRef]

87. Kvashnin, D.G.; Sorokin, P.B. Effect of ultrahigh stiffness of defective graphene from atomistic point of view. J. Phys. Chem. Lett. 2015, 6, 2384-2387. [CrossRef] [PubMed]

88. Lee, G.; Yang, G.; Cho, A.; Han, J.W.; Kim, J. Defect-engineered graphene chemical sensors with ultrahigh sensitivity. Phys. Chem. Chem. Phys. 2016, 18, 14198-14204. [CrossRef] [PubMed]

89. Warner, J.H.; Margine, E.R.; Mukai, M.; Robertson, A.W.; Giustino, F.; Kirkland, A.I. Dislocation-driven deformations in graphene. Science 2012, 337, 209-212. [CrossRef] [PubMed]

90. Jeong, B.W.; Ihm, J.; Lee, G.D. Stability of dislocation defect with two pentagon-heptagon pairs in graphene. Phys. Rev. B Condens. Matter 2008, 78, 165403. [CrossRef]

91. Grantab, R.; Shenoy, V.B.; Ruoff, R.S. Anomalous strength characteristics of tilt grain boundaries in graphene. Science 2010, 330, 946-948. [CrossRef] [PubMed]

92. Wei, Y.; Wu, J.; Yin, H.; Shi, X.; Yang, R.; Dresselhaus, M. The nature of strength enhancement and weakening by pentagon-heptagon defects in graphene. Nat. Mater. 2012, 11, 759-763. [CrossRef] [PubMed]

93. Song, Z.G.; Artyukhov, V.I.; Yakobson, B.I.; Xu, Z.P. Pseudo hall-petch strength reduction in polycrystalline graphene. Nano Lett. 2013, 13, 1829-1833. [CrossRef] [PubMed]

94. Sha, Z.D.; Quek, S.S.; Pei, Q.X.; Liu, Z.S.; Wang, T.J.; Shenoy, V.B.; Zhang, Y.W. Inverse pseudo hall-petch relation in polycrystalline graphene. Sci. Rep. UK 2014, 4, 5991. [CrossRef] [PubMed]

95. Liu, T.H.; Pao, C.W.; Chang, C.C. Effects of dislocation densities and distributions on graphene grain boundary failure strengths from atomistic simulations. Carbon 2012, 50, 3465-3472. [CrossRef]

96. Nair, R.R.; Blake, P.; Grigorenko, A.N.; Novoselov, K.S.; Booth, T.J.; Stauber, T.; Peres, N.M.R.; Geim, A.K. Fine structure constant defines visual transparency of graphene. Science 2008, 320, 1308. [CrossRef] [PubMed]

97. Bolotin, K.I.; Sikes, K.J.; Jiang, Z.; Klima, M.; Fudenberg, G.; Hone, J.; Kim, P.; Stormer, H.L. Ultrahigh electron mobility in suspended graphene. Solid State Commun. 2008, 146, 351-355. [CrossRef]

98. Pereira, V.M.; Castro Neto, A.H. Strain engineering of graphene's electronic structure. Phys. Rev. Lett. 2009, 103, 046801. [CrossRef] [PubMed]

99. Gui, G.; Li, J.; Zhong, J.X. Band structure engineering of graphene by strain: First-principles calculations. Phys. Rev. B 2008, 78, 075435. [CrossRef]

100. Ni, Z.H.; Yu, T.; Lu, Y.H.; Wang, Y.Y.; Feng, Y.P.; Shen, Z.X. Uniaxial strain on graphene: Raman spectroscopy study and band-gap opening. ACS Nano 2008, 2, 2301-2305. [CrossRef] [PubMed]

101. Pereira, V.M.; Castro Neto, A.H.; Peres, N.M.R. Tight-binding approach to uniaxial strain in graphene. Phys. Rev. B 2009, 80, 045401. [CrossRef]

102. Guinea, F.; Katsnelson, M.I.; Geim, A.K. Energy gaps and a zero-field quantum hall effect in graphene by strain engineering. Nat. Phys. 2010, 6, 30-33. [CrossRef]

103. Farjam, M.; Rafii-Tabar, H. Comment on "band structure engineering of graphene by strain: First-principles calculations". Phys. Rev. B 2009, 80, 167401. [CrossRef]

104. Huang, M.Y.; Pascal, T.A.; Kim, H.; Goddard, W.A.; Greer, J.R. Electronic-mechanical coupling in graphene from in situ nanoindentation experiments and multiscale atomistic simulations. Nano Lett. 2011, 11, 1241-1246. [CrossRef] [PubMed]

105. Cocco, G.; Cadelano, E.; Colombo, L. Gap opening in graphene by shear strain. Phys. Rev. B 2010, 81, 241412. [CrossRef]

106. Choi, S.M.; Jhi, S.H.; Son, Y.W. Effects of strain on electronic properties of graphene. Phys. Rev. B 2010, 81, 081407. [CrossRef]

107. Verberck, B.; Partoens, B.; Peeters, F.M.; Trauzettel, B. Strain-induced band gaps in bilayer graphene. Phys. Rev. B 2012, 85, 125403. [CrossRef]

108. Choi, S.M.; Jhi, S.H.; Son, Y.W. Controlling energy gap of bilayer graphene by strain. Nano Lett. 2010, 10, 3486-3489. [CrossRef] [PubMed]

109. Ramasubramaniam, A.; Naveh, D.; Towe, E. Tunable band gaps in bilayer graphene-bn heterostructures. Nano Lett. 2011, 11, 1070-1075. [CrossRef] [PubMed] 
110. Son, Y.W.; Cohen, M.L.; Louie, S.G. Half-metallic graphene nanoribbons. Nature 2006, 444, 347-349. [CrossRef] [PubMed]

111. Lherbier, A.; Biel, B.; Niquet, Y.M.; Roche, S. Transport length scales in disordered graphene-based materials: Strong localization regimes and dimensionality effects. Phys. Rev. Lett. 2008, 100, 036803. [CrossRef] [PubMed]

112. Mondal, H.S.; Hossain, M.M.; Rahaman, M.E.; Amin, S.M.B.; Hossain, M.B.; Hasan Mahasin, M.M.; Mondal, P.K. Optoelectronics based dynamic advancement of graphene: Characteristics and applications. Crystals 2018, 8, 171. [CrossRef]

113. Ong, M.T.; Reed, E.J. Engineered piezoelectricity in graphene. ACS Nano 2012, 6, 1387-1394. [CrossRef] [PubMed]

114. Chandratre, S.; Sharma, P. Coaxing graphene to be piezoelectric. Appl. Phys. Lett. 2012, 100, 023114. [CrossRef]

115. Parshani, R.; Rozenblat, C.; Ietri, D.; Ducruet, C.; Havlin, S. Inter-similarity between coupled networks. EPL-Europhys. Lett. 2010, 92, 68002. [CrossRef]

116. Fampiou, I.; Ramasubramaniam, A. Binding of pt nanoclusters to point defects in graphene: Adsorption, morphology, and electronic structure. J. Phys. Chem. C 2012, 116, 6543-6555. [CrossRef]

117. Zhu, J.Y.; Childress, A.S.; Karakaya, M.; Dandeliya, S.; Srivastava, A.; Lin, Y.; Rao, A.M.; Podila, R. Defect-engineered graphene for high-energy- and high-power-density supercapacitor devices. Adv. Mater. 2016, 28, 7185-7192. [CrossRef] [PubMed]

118. Pellegrino, F.M.D.; Angilella, G.G.N.; Pucci, R. Strain effect on the optical conductivity of graphene. Phys. Rev. B 2010, 81, 035411. [CrossRef]

119. Yan, H.; Ku, P.C.; Gan, Z.Y.; Liu, S.; Li, P. Strain effects in gallium nitride adsorption on defective and doped graphene: First-principles calculations. Crystals 2018, 8, 58. [CrossRef]

120. Elias, D.C.; Nair, R.R.; Mohiuddin, T.M.G.; Morozov, S.V.; Blake, P.; Halsall, M.P.; Ferrari, A.C.; Boukhvalov, D.W.; Katsnelson, M.I.; Geim, A.K.; et al. Control of graphene's properties by reversible hydrogenation: Evidence for graphane. Science 2009, 323, 610-613. [CrossRef] [PubMed]

121. Kresse, G.; Furthmuller, J. Efficiency of ab-initio total energy calculations for metals and semiconductors using a plane-wave basis set. Comput. Mater. Sci. 1996, 6, 15-50. [CrossRef]

122. Kresse, G. Ab-initio molecular-dynamics for liquid-metals. J. Non-Cryst. Solids 1995, 193, 222-229. [CrossRef]

123. Kresse, G.; Furthmuller, J. Efficient iterative schemes for ab initio total-energy calculations using a plane-wave basis set. Phys. Rev. B 1996, 54, 11169-11186. [CrossRef]

124. Zhao, H.; Aluru, N.R. Temperature and strain-rate dependent fracture strength of graphene. J. Appl. Phys. 2010, 108, 064321-064325. [CrossRef]

125. Fasolino, A.; Los, J.H.; Katsnelson, M.I. Intrinsic ripples in graphene. Nat. Mater. 2007, 6, 858-861. [CrossRef] [PubMed]

126. Gao, W.; Huang, R. Thermomechanics of monolayer graphene: Rippling, thermal expansion and elasticity. J. Mech. Phys. Solids 2014, 66, 42-58. [CrossRef]

127. Peng, Q.; Dearden, A.K.; Crean, J.; Han, L.; Liu, S.; Wen, X.; De, S. New materials graphyne, graphdiyne, graphone, and graphane: Review of properties, synthesis, and application in nanotechnology. Nanotechnol. Sci. Appl. 2014, 7, 1-29. [CrossRef] [PubMed]

128. Poh, H.L.; Sanek, F.; Sofer, Z.; Pumera, M. High-pressure hydrogenation of graphene: Towards graphane. Nanoscale 2012, 4, 7006-7011. [CrossRef] [PubMed]

129. Peng, Q.; Liang, C.; Ji, W.; De, S. A theoretical analysis of the effect of the hydrogenation of graphene to graphane on its mechanical properties. Phys. Chem. Chem. Phys. 2013, 15, 2003-2011. [CrossRef] [PubMed]

130. Zhou, J.; Sun, Q. How to fabricate a semihydrogenated graphene sheet? A promising strategy explored. Appl. Phys. Lett. 2012, 101, 073114. [CrossRef]

131. Hussain, T.; De Sarkar, A.; Ahuja, R. Strain induced lithium functionalized graphane as a high capacity hydrogen storage material. Appl. Phys. Lett. 2012, 101, 103907. [CrossRef]

132. Fiori, G.; Lebegue, S.; Betti, A.; Michetti, P.; Klintenberg, M.; Eriksson, O.; Iannaccone, G. Simulation of hydrogenated graphene field-effect transistors through a multiscale approach. Phys. Rev. B 2010, 82, 153404. [CrossRef]

133. Horiuchi, S.; Kumai, R.; Tokura, Y. Hydrogen-bonding molecular chains for high-temperature ferroelectricity. Adv. Mater. 2011, 23, 2098-2103. [CrossRef] [PubMed] 
134. Slepchenkov, M.M.; Barkov, P.V.; Glukhova, O.E. High-density hydrogen storage in a 2D-matrix from graphene nanoblisters: A prospective nanomaterial for environmentally friendly technologies. Crystals 2018, 8, 161. [CrossRef]

135. Da, H.; Feng, Y.P.; Liang, G. Transition-metal-atom-embedded graphane and its spintronic device applications. J. Phys. Chem. C 2011, 115, 22701-22706. [CrossRef]

136. Baughman, R.H.; Eckhardt, H.; Kertesz, M. Structure-property predictions for new planar forms of carbon-layered phases containing $\mathrm{sp}^{2}$ and sp atoms. J. Chem. Phys. 1987, 87, 6687-6699. [CrossRef]

137. Coluci, V.R.; Braga, S.F.; Legoas, S.B.; Galvao, D.S.; Baughman, R.H. Families of carbon nanotubes: Graphyne-based nanotubes. Phys. Rev. B 2003, 68, 035430. [CrossRef]

138. Baughman, R.H.; Galvao, D.S.; Cui, C.X.; Wang, Y.; Tomanek, D. Fullereneynes-A new family of porous fullerenes. Chem. Phys. Lett. 1993, 204, 8-14. [CrossRef]

139. Peng, Q.; Ji, W.; De, S. Mechanical properties of graphyne monolayers: A first-principles study. Phys. Chem. Chem. Phys. 2012, 14, 13385-13391. [CrossRef] [PubMed]

140. Cranford, S.W.; Buehler, M.J. Mechanical properties of graphyne. Carbon 2011, 49, 4111-4121. [CrossRef]

141. Zhang, Y.Y.; Pei, Q.X.; Wang, C.M. Mechanical properties of graphynes under tension: A molecular dynamics study. Appl. Phys. Lett. 2012, 101, 081909. [CrossRef]

142. Malko, D.; Neiss, C.; Vines, F.; Gorling, A. Competition for graphene: Graphynes with direction-dependent dirac cones. Phys. Rev. Lett. 2012, 108, 086804. [CrossRef] [PubMed]

143. Romero-Aburto, R.; Narayanan, T.N.; Nagaoka, Y.; Hasumura, T.; Mitcham, T.M.; Fukuda, T.; Cox, P.J.; Bouchard, R.R.; Maekawa, T.; Kumar, D.S.; et al. Fluorinated graphene oxide; a new multimodal material for biological applications. Adv. Mater. 2013, 25, 5632-5637. [CrossRef] [PubMed]

144. Wang, X.; Wang, W.M.; Xu, D.Z.; Liu, Y.; Lai, W.C.; Liu, X.Y. Activation effect of porous structure on fluorination of graphene based materials with large specific surface area at mild condition. Carbon 2017, 124, 288-295. [CrossRef]

145. Dubois, M.; Guerin, K.; Ahmad, Y.; Batisse, N.; Mar, M.; Frezet, L.; Hourani, W.; Bubendorff, J.L.; Parmentier, J.; Hajjar-Garreau, S.; et al. Thermal exfoliation of fluorinated graphite. Carbon 2014, 77, 688-704. [CrossRef]

146. Feng, W.; Long, P.; Feng, Y.Y.; Li, Y. Two-dimensional fluorinated graphene: Synthesis, structures, properties and applications. Adv. Sci. 2016, 3, 1500413. [CrossRef] [PubMed]

147. Shi, M.X.; Kan, Q.H.; Sha, Z.D.; Kang, G.Z. The edge-related mechanical properties of fluorographene nanoribbons. J. Appl. Mech. ASME 2015, 82, 041007. [CrossRef]

148. Gan, C.K.; Srolovitz, D.J. First-principles study of graphene edge properties and flake shapes. Phys. Rev. $B$ 2010, 81, 125445. [CrossRef]

149. Huang, B.; Liu, M.; Su, N.H.; Wu, J.; Duan, W.H.; Gu, B.L.; Liu, F. Quantum manifestations of graphene edge stress and edge instability: A first-principles study. Phys. Rev. Lett. 2009, 102, 166404. [CrossRef] [PubMed]

150. Adak, N.C.; Chhetri, S.; Murmu, N.C.; Samanta, P.; Kuila, T. Effect of thermally reduced graphene oxide on mechanical properties of woven carbon fiber/epoxy composite. Crystals 2018, 8, 111. [CrossRef]

151. Chi, E.Y.; An, M.F.; Yao, G.B.; Tian, F.; Wang, Z.B. The influence of epitaxial crystallization on the mechanical properties of polyamide 66/reduced graphene oxide nanocomposite injection bar. Crystals 2017, 7, 384. [CrossRef]

152. Dikin, D.A.; Stankovich, S.; Zimney, E.J.; Piner, R.D.; Dommett, G.H.B.; Evmenenko, G.; Nguyen, S.T.; Ruoff, R.S. Preparation and characterization of graphene oxide paper. Nature 2007, 448, 457-460. [CrossRef] [PubMed]

153. Xiang, C.S.; Young, C.C.; Wang, X.; Yan, Z.; Hwang, C.C.; Cerioti, G.; Lin, J.; Kono, J.; Pasquali, M.; Tour, J.M. Large flake graphene oxide fibers with unconventional 100\% knot efficiency and highly aligned small flake graphene oxide fibers. Adv. Mater. 2013, 25, 4592-4597. [CrossRef] [PubMed]

154. Xu, Z.; Zhang, Y.; Li, P.G.; Gao, C. Strong, conductive, lightweight, neat graphene aerogel fibers with aligned pores. ACS Nano 2012, 6, 7103-7113. [CrossRef] [PubMed]

155. Kim, S.M.; Song, E.B.; Lee, S.; Seo, S.; Seo, D.H.; Hwang, Y.; Candler, R.; Wang, K.L. Suspended few-layer graphene beam electromechanical switch with abrupt on-off characteristics and minimal leakage current. Appl. Phys. Lett. 2011, 99, 023103. [CrossRef] 
156. Kang, J.W.; Kim, H.W.; Kim, K.S.; Lee, J.H. Molecular dynamics modeling and simulation of a graphene-based nanoelectromechanical resonator. Curr. Appl. Phys. 2013, 13, 789-794. [CrossRef]

157. Cheng, H.H.; Hu, Y.; Zhao, F.; Dong, Z.L.; Wang, Y.H.; Chen, N.; Zhang, Z.P.; Qu, L.T. Moisture-activated torsional graphene-fiber motor. Adv. Mater. 2014, 26, 2909-2913. [CrossRef] [PubMed]

(c) 2018 by the authors. Licensee MDPI, Basel, Switzerland. This article is an open access article distributed under the terms and conditions of the Creative Commons Attribution (CC BY) license (http://creativecommons.org/licenses/by/4.0/). 